36

BNL 51439

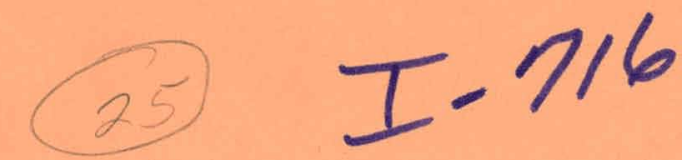

\title{
MICROCAVITY HYDROGEN STORAGE FINAL PROGRESS REPORT
}

\author{
ROBERT J. TEITEL ASSOCIATES \\ 9145 Chesapeake Drive \\ P.0. Box 81921
}

San Diego, California 92138

May 1981

Work supported by the

DIVISION OF PHYSICAL AND CHEMICAL ENERGY STORAGE

OFFICE OF ENERGY SYSTEMS RESEARCH

UNITED STATES DEPARTMENT OF ENERGY

DEPARTMENT OF ENERGY AND ENVIRONMENT

BROOKHAVEN NATIONAL LABORATORY UPTON, NEW YORK 11973 


\section{DISCLAIMER}

This report was prepared as an account of work sponsored by an agency of the United States Government. Neither the United States Government nor any agency Thereof, nor any of their employees, makes any warranty, express or implied, or assumes any legal liability or responsibility for the accuracy, completeness, or usefulness of any information, apparatus, product, or process disclosed, or represents that its use would not infringe privately owned rights. Reference herein to any specific commercial product, process, or service by trade name, trademark, manufacturer, or otherwise does not necessarily constitute or imply its endorsement, recommendation, or favoring by the United States Government or any agency thereof. The views and opinions of authors expressed herein do not necessarily state or reflect those of the United States Government or any agency thereof. 


\section{DISCLAIMER}

Portions of this document may be illegible in electronic image products. Images are produced from the best available original document. 


\title{
MICROCAVITY HYDROGEN STORAGE FINAL PROGRESS REPORT
}

\author{
R.J. Teitel \\ ROBERT J. TEITEL ASSOCIATES \\ 9145 Chesapeake Drive \\ P.0. Box 81921 \\ San Diego, California 92138 \\ Subcontract No. 511197-S \\ BNL -51439 \\ DE82 006969 \\ May 1981
}

Prepared for

ENERGY STORAGE AND CONVERSION DIVISION DEPARTMENT OF ENERGY AND ENVIRONMENT

- BROOKHAVEN NATIONAL LABORATORY

ASSOCIATED UNIVERSITIES, INC.

UPTON, NEW YORK 11973

Under Contract No. DE-ACO2-76CH00016 with the UNITED STATES DEPARTMENT OF ENERGY 


\section{DISCLAIMER}

This report was prepared as an account of work sponsored by an agency of the United States Government. Neither the United States Guver 'nment nor any agency thereof, nor any of their employees, nor any of their contractors, subcontractors, 0 : their employees, makes any warranty, express or implied, or assumes any legal liability or responsibility for the accuracy, completeness, or usefulness of any information, apparatus, product, or process disclosed, or represents that its use would not infringe privately owned rights. Reference herein to any specific commercial product, process, or service by trade name, trademark, manufacturer, or otherwise, does not necessarily constitute or imply its cndorsement, recommendation, or favoring by the United States Government or any agency, contractor or subcontractor thereof. The views and opinions of authors expressed herein do not necessarily state or reflect those of the United States Government ur any agency, contractor or subcontractor thereof.

Printed in the United States of America Available from

National Technical Information Service

U.S. Department of Comnerce

5285 Port Royal Road

Springfield, VA 22161

NTIS price codes:

Printed Copy: A03; Microfiche Copy: A01 
Table of Contents ........................ iii

List of Figures $\ldots \ldots \ldots \ldots \ldots \ldots \ldots \ldots \ldots \ldots \ldots \ldots$ iv

List of Tables.......................... iv

Abstract $\ldots \ldots \ldots \ldots \ldots \ldots \ldots \ldots \ldots \ldots \ldots \ldots \ldots \ldots \ldots \ldots$ v

1.0 Int roduction $\ldots \ldots \ldots \ldots \ldots \ldots \ldots \ldots \ldots \ldots \ldots \ldots \ldots \ldots \ldots$

2.0 Objectives $\ldots \ldots \ldots \ldots \ldots \ldots \ldots \ldots \ldots \ldots \ldots \ldots \ldots \ldots \ldots \ldots 2$

3.0 Task Description ........................ 2

3.1 Program Plan (Task 1).................... 2

3.2 Microsphere Bed Preparation (Task 2) .......... 2

3.3 Screen Tests (Task 3) .................... 2

3.4 Microsphere Optimization Tests (Task 4)........ 3

3.5 Storage Cost Estimates (T ask 5) ............. 3

3.6 Cyclic Tests (Task 6).................... 4

4.0 Microsphere Bed Preparation (Task 2) ............. 4

4.1 Fill Apparatus ....................... 4

4.2 Microsphere Bed Filling Operation ............ 6

4.3 Bed Characterization ................... 6

5.0 Screening Tests (Task 3)................... 7

5.1 Test Procedures ..................... 7

5.1.1 Sink-Float Separation .............. 8

5.1.2 Surface Analyses ................... 8

5.1.3 Density Measurements................ 8

5.1.4 Pressure Measurements............... 8

5.1.5 Microscopic Analyses................ 8

5.1.6 Hydrogen Flow Measurements ............ 9

5.1 .7 Chemical Analyses ................. 9

5.1 .8 Crush Tests ...................... 9

5.1 .9 Hydrogen Filling Operation............. 9

5.1.10 Hydrogen Dispensing Test ............ 10

5.2 Data Evaluation..................... 10

5.3 Test Results ........................12

5.3 .1 Chemical Analyses................12

5.3 .2 Particle Dimensional Analyses ..........12

5.3 .3 Dimensional Analysis .............. 13

5.3 .4 Microscopic Analyses.................13

5.3 .5 Crush Test Results ..................13

5.3.6 Screening Test Results ...............14

5.3.7 Fill-Dispense Tests.................14

6.0 Microsphere Modification (Task 4) ............ 17

7.0 Discussion............................ 19

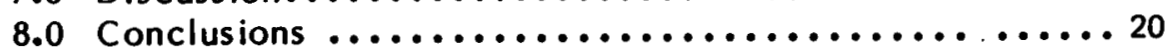

9.0 Recommendations ....................... 20

Acknowledgements .........................21

References ................................ 21

A ddendum to Conclusions $\ldots \ldots \ldots \ldots \ldots \ldots \ldots \ldots \ldots \ldots \ldots \ldots 21$ 


\section{LIST OF FIGURES}

Figure $1-$ Large Fill Vessel .......................... 31

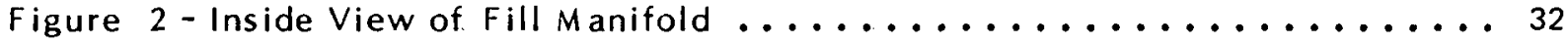

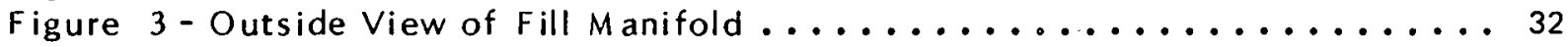

Figure 4 - Hood Enclosure ......................... 33

Figure 5 - Two-Stage Diaphragm-Type Compressor .............. 33

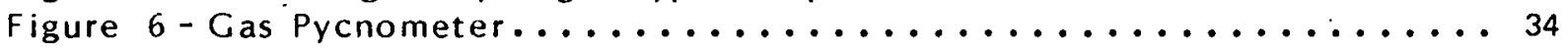

Figure 7 - Hydrogen Dispensing Apparatus.................... 35

Figure $8-$ Small Fill Vessel ............................. 35

Figure $9-$ Microspheres ............................. 36

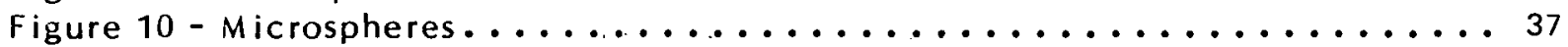

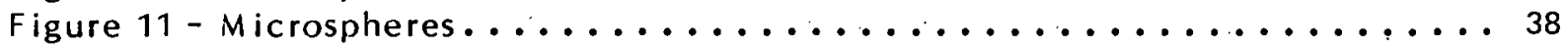

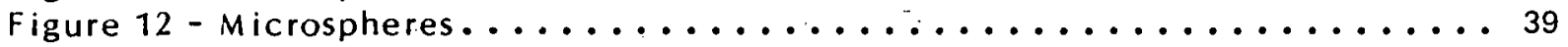

Figure $13-$ Crush Treatment of $3 M-D 32 / 4500$ Grade $\ldots \ldots \ldots \ldots \ldots$

Figure $14 .-$ Crush Treatment of Emerson \& Cuming Grade . . . . . . . . . . 40

\section{TABLES}

Table $1-I_{n}$ arge Scale Filling Study Dispense Test Results............... 23

Table 2 -Screening Tests Results ........................... 24

Table 3 - Chemical Analyses Results...................... 25

Table 4 - Microscopic Analyses of Microspheres ................. 26

Table 5 - Microsphere Crush Test Results ...................... 27

Table 6 - Fill-Dispense Test Results ...................... 28

Table 7 - Update of 1979 Test Results....................... 29

Table 8 - Survey of Particle Size Improvements .................. 30 


\begin{abstract}
ABST RACT
In the microcavity storage system, high pressure hydrogen is stored in hollow, glass microspheres, $5-150 \mu \mathrm{m}$. This report presents the results of an experimental study to evaluate the performance of commercially available microspheres for this application. Eight grades were evaluated and their characteristics are presented. A substantial fraction of the microsphere beds survived the conditions of storing hydrogen at pressures of $400 \mathrm{~atm}$. establishing that the concept of high pressure hydrogen storage is feasible. Information was gathered on the properties of the survivor microspheres. Processes for their selective recovery are being investigated.
\end{abstract}




\subsection{INTRODUCTION}

The use of micron size, hollow, glass spheres (microspheres) as a container for high pressure hydrogen (microcavity hydrogen storage) was proposed by Robert J. Teitel Associates (RJTA) in 1977.(1) Hydrogen is admitted and dispensed from the spheres by permeation through the glass walls of the microspheres. The rate of hydrogen transfer depends upon the hydrogen pressure gradient across the microsphere wall, the temperature, the glass composition and the microsphere dimensions. The strength of the glass and microsphere dimensions limit the maximum hydrogen storage pressure. The first DOE sponsored study (1978) established that the concept, when designed for automotive hydrogen storage, had potential economic and weight advantages over an advanced metal hydride storage system $\left(\mathrm{MgH}_{\mathbf{x}}+(\mathrm{Ti}, \mathrm{Fe}, \mathrm{Mn}) \mathrm{H}_{\mathrm{x}}\right)^{(\mathrm{i})}$ On the other hand, the microcavity system would require a greater volume. Engineering studies of the automotive hydrogen storage system and the associated microsphere filling plant were performed. Estimated costs for filling microspheres with hydrogen were not prohibitively high. Additional filling plant economic studies were conducted in 1979 and they indicated that filling costs estimated in 1978 could be reduced to half by moving the microsphere bed during the operation. In all of these system studies, there was no effort to optimize the system for the application.

In 1979, two commercial grades of microspheres ( $3 M-D 32 / 4500$ and Fillite 200/.7) were selected and evaluated experimentally. This selection was based upon the results of prior studies and vendor information. (1) Heat treated 3M-D32/4500 came close to meeting the requirements for automotive applications. ${ }^{(2)}$ Hydrogen weight densities between 0.056 and 0.065 g. $\mathrm{H}_{2} / \mathrm{g}$. bed were attained experimentally with minimal breakage. The maximum stored hydrogen without breakage was at a pressure of $\backsim 300$ atm ( $\sim 4500$ psi.) at room teinperature.

This year, the experimental investigation was extended to the evaluation of eight commercial grades in a search for microsphere sources which can store hydrogen at higher pressures. Unlike last years study, the application was not specific to the automotive hydrogen storage. The 1980 program consisted of eight tasks which included the six technical tasks listed below.

$\begin{array}{ll}\text { Task } 1 & \text { Program Plan } \\ \text { Task } 2 & \text { Microsphere Bed Preparation } \\ \text { Task } 3 & \text { Screen Tests } \\ \text { Task } 4 & \text { Microsphere Optimization Tests } \\ \text { Task } 5 & \text { Storage Cost Estimates } \\ \text { Task } 6 & \text { Cycle Testing }\end{array}$

This report summarizes the accomplishments on Tasks 2, 3, and that part of Task 4 completed in the period of March 15, 1980-November 1, 1980 prior to a redirection of the program. Recommendations for future studies were derived from a review of all of the DOE funded experimental information accumulated thus far. 


\subsection{OBJECTIVES}

Objectives of the 1980 program, as they appear in the Program Plan, were as follows:

1. To develop a systematic screening procedure for the evaluation of commercially available candidate grades of microspheres in order to direct further efforts on only the most promising microsphere grades and sources. A minimum of eight grades of microspheres will be screened and the results compared on a weighted parameter basis which will include parameters such as: hydrogen storage capacity; breakage due to room temperature pressurization and handling; and, initial cost.

2. To study the characteristics of microsphere beds on a larger than bench-scale basis, three cubic feet of the most promising microsphere grade, selected by RJTA, will be prepared for dispension testing at BNL. Two cubic feet of microspheres will be filled with hydrogen by RJTA and shipped. One cubic foot of microspheres will be shipped empty.

3. To use various optimization techniques to improve the performance of a minimum of two "best-candidate" microsphere beds identified by the screening test results.

4. To establish cost and practicable performance parameters for the two most promising microsphere sources and grades.

5. To estimate the fill and maintenance costs for a bed of microsphere in order to better assess the viability of microcavity hydrogen storage systems.

\subsection{TASK DESCRIPTION}

The technical tasks of the program are described below:

\subsection{Program Plan (Task 1 )}

A program plan will be prepared to include test criteria, goals and acceptable values for storage capacity, permeability rate, cost and attrition for several example applications.

\subsection{Microsphere Bed Preparation (Task 2)}

Threc cubic feet of microspheres will be acquired by RJTA and prepared for filling. Two, one cubic foot beds are to be filled to the highest at tainable pressure, on a best efforts basis, and all material ( $2 \mathrm{ft}^{3}$ filled and $1 \mathrm{ft}^{3}$ empty) shipped to $B N L$ for dispension testing. This effort will include: the design and construction of a $0.25 \mathrm{cu} . \mathrm{ft}$. fill vessel, filling operations, annealing treatments, microsphere procurement verification of the microsphere bed properties and shipment of the microsphere beds to BNL.

\subsection{Screen Tests (Task 3)}

Standardized test procedures will be developed. Tests will be performed to screen a minimum of eight grades of commercially available microspheres. Two grades most consistent with cost-performance requirements for the microcavity storage system will 
be selected for further study. This task will include the following tests as a minimum to characterize the beds and evaluate the microsphere grades:

Crush Tests - Three room temperature pressurization cycles from 0-400 atmospheres, will be followed by a sink-float survivor evaluation to determine the strength of the microsphere bed. Inquiries will be made of the suppliers to assess the impact of any material losses on costs.

Chemical Analyses - The glass composition (metal oxides only) will be determined by standard chemical analytical methods.

Microsphere Size Analyses - Subjective microsphere bed information on particle size distribution, bed surface area, particle density, glass density and bulk density will be evaluated.

Fill-Dispense Tests - Small beds of microspheres will be filled under a pressure of $\backsim 800$ atm. $(12,000 \mathrm{psi})$ of hydrogen at $350^{\circ} \mathrm{C}$ using a standardized heating and pressurization procedure. The microsphere bed temperature will then be reduced to dry ice temperature, $-77^{\circ} \mathrm{C}$, and the fill vessel gas pressure will be reduced to 1 at $\mathrm{m}$. After at least one hour, the temperature of the bed will be increased using a standardized schedule to $400^{\circ} \mathrm{C}$. The total hydrogen dispensed during the heating cycle will be measured and the total storage capactity of each grade documented. Breakage will be assessed after the test by a standard sink-float analysis. A critical point of the test will be the volume of $\mathrm{H}_{2}$ available at temperatures below 200,250 and $350^{\circ} \mathrm{C}$ at rates above a minimum $\mathrm{H}_{2}$ flow rate required by typical applications. These will be recorded also.

\subsection{Microsphere Optimization Tests (Task 4)}

Two grades of commercially available microspheres that best meet the criteria defined in Task 1 will be optimized by applying one or more of the following operations.

a. Particle size separations.

b. Surface treatments, such as leaching, in order to adjust the permeability rates to better fit typical applications for the storage system.

c. Stress relief by heat treatment to reduce breakage and increase storage capacity.

d. Overpressurization treatments to eliminate weak microspheres.

The performance of the survivors will to be evaluated and the impact of the operation on microsphere costs assessed.

\subsection{Storage Cost Estimates (Task 5)}

Based upon available information from microsphere manufacturers and estimated filling operations, an estimate of the filled microsphere bed costs and bed maintanence costs will be developed. Anticipated attrition loss due to cycling will be taken into account. A thoroughly detailed and referenced cost breakdown will be provided. A plant study, construction and operating costs for microsphere manufacture and bed filling will be completed. 


\subsection{Cyclic Tests (Task 6)}

Cyclic tests (filling and dispensing) of the "best-candiate" materials, after optimization, will be conducted to assess microsphere attrition under prolonged cycling. The test program will involve no less than ten fill-dispense cycles on each sample tested. A minimum of two grades of microspheres will be tested.

\subsection{MICROSPHERE BED PREPARATION (Task 2)}

The principal object of this task was to fill 2-one cu. $\mathrm{ft}$. microsphere beds for BNL testing and charcterization. In addition to this, the task provided an opportunity to establish whether small scale tests $(1-5 c c$ beds) give the same results as larger scale tests. Since the fill vessel could fill $0.25 \mathrm{cu}$. $\mathrm{ft}$. at a time, the reproducibility of the filling operations on a semi-large scale could be evaluated. This task also provided information on the consistancy of microsphere performance from one lot to another of the same commercial grade since a new lot of microspheres had to be ordered for this part of the program.

\subsection{Fill Apparatus}

The following equipment is essential in a large microsphere bed filling facility:

1. A fill vessel capable of subjecting microspheres to pressures of $\backsim 12,000$ psi at temperatures between $350-400^{\circ} \mathrm{C}$;

2. A compressor capable of supplying pure hydrogen at high pressures in a reasonable time;

3. Heaters capable of raising the temperature of the fill vessel to operating temperature in a reasonable time;

4. A gas manifold equipped with suitable instrumentation for measuring temperature and pressure;

5. A vacuum pump to exclude air from the fill vessel prior to microsphere filling operations.

R JTA conducted a survey of facilities that could provide the above specified conditions for filling microspheres. Most facilities found were lacking one or more of the necessary capabilities, except Rockwell International's facilities in Canoga Park, Ca.. Their equipment was designed to conduct metallurgical tests on materials at elevated temperatures in high pressure hydrogen environments. Due to circumstances beyond their control, these facilities were heavily engaged and not available to $R J T A$.

R JTA requested and obtained funds to build a $0.25 \mathrm{cu}$. $\mathrm{ft}$. fill vessel for this program. Pre-fabricated, thick wall, right cylindrical chambers with large access ports were considered at first. These vessels are machined from forged billets which required long lead-time scheduling (6 months to 1 year) and were very expensive (over $\$ 25,000$ ). The machining costs were high primarily because of the large port. In addition, expensive metal gaskets were required for high pressure seals. Procurement of this type of vessel was beyond the funding level and schedule of this program.

The vessel design finally adopted was a cluster of seven heavy wall tubes having a total internal volume of $0.25 \mathrm{cu}$. $\mathrm{ft}$. One of these tubes is shown in Figure $1 \mathrm{~A}$. The tubes 
are made of 316 stainless steel and are $2.5 \mathrm{in.} O D$ by $1.25 \mathrm{in.}$ ID by $6 \mathrm{ft}$. long. This design meets ASTM Pressure Vessel Design Codes. The vessel is designed to operate at 600$700^{\circ} \mathrm{F}$ at vessel pressures up to $\backsim 11,300$ psi. The vessel was less expensive and was available in time for the filling operations. As shown in Figure $1 \mathrm{~A}$, heating elements are wound about each tube. Access openings are located at both ends of the tubes and have a diameter of $0.75 \mathrm{in.}$

An especially designed, high pressure end closure was fitted into both ends of each tube. Figure 1B shows the end plug assembly. The lower part is a plug with a tapered end which rests on a beveled ledge machined into the tube to form a seal closure. Pressure was applied to the seal by means of a collet (at top) threaded into the end of the tube. Movement of collet against the stationary plug was assured by a hardened steel washer coated with Molykote $G-n$ paste. A stainless steel frit (not shown in the figure) was press fitted inside the tapered end of the plug. This frit restricted the movement of the microsphere bed during the filling operation. It is well known that threaded stainless steel joints gall and freeze when heated under high pressure. This problem was averted by using a collet made of a high strength bronze (grade AMPCO 18 or 45). The top end of the plug provided for a coupling to standard super pressure tubing, shown on an adjacent tube in Figure $1 \mathrm{~B}$.

The fill vessel tubes and end closures were hydrostatically proof tested to 20,000 psi. The pressure was cycled 3 times with a $0.5 \mathrm{hr}$. hold on the third cycle. No difficulties were encountered and all tubes met ASTM pressure vessel code standards.

Fill tube temperatures are sensed by thermocouples attached externally and located at mid-length of each tube. Tests were performed on loaded fill tubes using thermocouples on the inside of the tube. They verified that the temperature was reasonably uniform along the tube and that the temperature measured by the control thermocouple outside the tube agreed with the temperature measured within. Voltage outputs from each fill tube thermocouple, using the selector switch shown in Figure 7 , were measured by a digital voltmeter and translated into temperature values. Power to each tube heater was supplied through manually regulated solid-state voltage controllers (ColePalmer Model 2603). The heaters were Nichrome wire electrically insulated from the tube by porcelain beads. Each tube was thermally insulated by 2.25 in. thick Fiberglas pipe insulation (not shown). About one hour was required to heat the tubes to the fill temperature $\left(\sim 350^{\circ} \mathrm{C}\right)$.

A gas manifold (Figures 2 and 3 ) connected seven fill tubes to the compressor and vacuum pump. It was assembled using super pressure tubing, valves and fittings (all rated above $30,000 \mathrm{psi})$. Both Bourdon and transducer type pressure gages were used to measure pressure. Periodically, they were checked one against the other for calibration. High hydrogen pressure was supplied by a Superpressure, two-stage, diaphragm -type compressor capable of supplying pressures up to 30,000 psi (shown in Figure 5). Originally, the compressor was purchased for the small scale experiments but it proved adequate for the large fill vessel when a supply pressure of over 1000 psi was made available from tank hydrogen. The large fill vessel, tubes, manifold, gages, small scale fill vessels and high pressure compressor were housed in a hood enclosure (Figure 4) which was forced draft ventilated and the gases exhausted outside the laboratory. As a further precaution, a sand bag wall, partially shown in the figure, was constructed outside the enclosure to protect personnel in case of a mechanical failure. Figure 4 also 
shows the labyrinth ent rance to the hood in which the fill tubes, compressor and manifold were located. Valve stems from the manifold extended through the wall, as shown on Figure 3, to permit all operations to be controlled from outside the hood.

\subsection{Microsphere Bed Filling Operation}

Last year, $3 \mathrm{M}$ grade $\mathrm{D} 32 / 4500$ microsphere beds were found to be the most promising commercial grade although the dispense and storage properties were lower than desired (Table 7). This grade was selected for the large bed demonstration. Fifty pounds were ordered in preparation for the operation.

Procedures for the large microsphere bed filling operations were established in tests using small scale ( $5 \mathrm{cc}$ bed) fill-dispense equipment. Various annealing treatments were applied to the new lot (lot no. D1516-6) of $3 \mathrm{M}$ grade D32/4500 microspheres. It was soon discovered that the new lot of microspheres did not respond to treatment as did lot no. P5427-1 used in last years study. First of all, the microspheres tended to sinter at lower temperatures, thus limiting the anneal treatment conditions. During the screening tests conducted in Task 3, (section 5.0) the new lot was found to differ from the previous lot of microspheres in other ways.

A large batch anneal treatment of $485-500^{\circ} \mathrm{C}$ in a nitrogen atmosphere was selected although experiments indicated that the microsphere bed performance was not enhanced appreciably. Fill-dispense tests indicated that this lot like the previous was susceptable to breakage when the room temperature fill pressure exceeded $\backsim 300$ atm. Consequently, the pressure for the large bed filling operations was limited to $\checkmark 270$ atms. The maximum hydrogen storage weight density and the volume density was restricted accordingly.

After part of the microsphere bed was loaded into each fill tube through one of the end closures, the tube was sealed and attached to the inanifold along with six other tubes. The fill procedure was to heat the microsphere beds to $350^{\circ} \mathrm{C}$ under a vacuum and pressurize the beds in stages; 3000 psi. for one hour, 6000 psi. for one hour and 8000 psi. for $3 \mathrm{hrs}$. The tubes were then cooled and unloaded through both end-access ports. Vibration and sometimes mild prodding was required to get the microspheres to flow out. A minor amount of breakage ( 15 wt \%) was sufficient to impair the free flow characteristics of the bed.

A shake-down run was made on a single fill tube vessel ( 1 liter volume) prior to the main filling operations. Then, the full compliment of seven tubes was employed to produce eight batches of filled microspheres.

\subsection{Bed Characterization}

Table 1 compares dispense test results for the shake-down batch, the eight batches of the main filling operation, and a liter batch of $3 M-D 32 / 4500$ (lot no. P5427-1) microspheres. The parameters used in Table 1 are explained in section 5.0. These results show the variation in performance characteristics of the $0.25 \mathrm{cu}$. $\mathrm{ft}$. batches that made up the large beds sent to BNL. Average dispense characteristics of the eight-0.25 cu. ft. batches are also included in the table. Deviation from the average was about $\pm 10 \%$, which was within the precision of the measurements and sampling procedures employed. 
The shake-down batch had properties comparable to the average of the eight $0.25 \mathrm{cu} f \mathrm{f}$. batches. A one liter batch of the earlier D32/4500 microsphere lot (P5427-1), was heat treated at $580^{\circ} \mathrm{C}$ and tested. Its properties were close to that of the new lot even through the screening tests, which are reported in Section 5.0, indicated significant differences in their properties. When compared to last year's results on annealed P5427-1 ( $T$ able 7), both were inferior. No further effort was made to resolve this conflict.

\subsection{SCREENING TESTS (Task 3)}

Screening tests used to evaluate commercial microspheres were similar to those used in last years study. The scope of measurements conducted this year however was broadened. This year, a gas pycnometer was constructed and used to make particle density measurements. Last year, it was assumed that the aspect ratio (particle density) was the same throughout the bed and regardless of treatment or test conditions. This year, particle density measurements were taken before and after each test. Significant changes in particle density have been detected. Screening tests have been standardized to permit comparison of the various grades. Eight commercial grades of glass microspheres were selected for detailed evaluation by chemical analyses, physical measurements, crush tests and fill-dispense tests. Mathematical analyses were developed further for interpreting measured properties to obtain average bed characteristics of microsphere size, microsphere wall thickness, and aspect ratio (diameter/wall thickness).

Last year, a large quantity of information was obtained on microsphere grade $3 \mathrm{M}$ D32/4500, lot P5427-1.(2) Samples of this grade have been submitted to screening tests this year to compare and extend information on this microsphere grade. These results were compared to those for the new microsphere lot (D1516-6). This section of the progress report will discuss the test procedures, the data interpretation and results in that order.

\subsection{Test Procedures}

The screening test program employed standard test procedures for evaluating microsphere beds on a comparable basis. The physical and chemical analyses have been adopted from general procedures and are well established. However, the fill-dispense test is a unique test developed for this program. Fill-dispense tests are more complicated and require information from the rest of the tests to confirm the results. In order to compare grades, it was first necessary to assure that the sample microsphere bed was filled completely. There is no practical, direct method for measuring the hydrogen contained in the bed, non-distructively. Radio tracer techniques using tritium radioactivity have been used in the development of nuclear laser fusion fuel targets; but, this procedure was restricted to the examination of individual microspheres. Another procedure was to break individual microspheres under a viscose oil. The contained pressure was calculated by comparing the size of the bubble formed to the size of the microsphere measured by microscopic techniques. Again, this technique can only be applied to individual microspheres and was distructive. To apply either method to a microsphere bed would be laborious, expensive, and involve many tests to establish statistical averages. The method adopted for this program was to dispense the hydrogen from a weighed 
microsphere bed and determine an average hydrogen storage weight density directly. Other dispension characteristics such as hydrogen availability, breakage, and average particle density of survivors were also obtained froin the tests.

5.1.1 Sink-Float Separation - A sink-float separation was used to determine the quantity of whole microspheres remaining after a test or operation. A weighed sample of the resulting mixture of whole and broken microspheres was placed in a funnel and mixed with methyl alcohol, isopropyl alcohol, or water. Debris and broken microspheres settled while whole microspheres floated. The sinkers and floaters were recovered separately, dried, and weighed. Results are reported as weight percent whole microsphere survivors.

5.1.2 Surface Analyses - AVX Materials Division of AVS Corporation, San Diego, determined the surface area of the bed by a standard B.E.T. method. The results were reported as $\mathrm{m}^{2}$ per $\mathrm{gm}$ of bed.

5.1.3 Density Measurements - Microsphere and glass densities were measured by gas displacement using a gas pycnometer (Figure 6). The main components of the pycnometer are enumerated in the footnote in the figure.

The volume of the sample tube (1) includes the volume in the tubing between the two isolation valves (2) located above the sample tube. This volume was calibrated by measuring the free volume in the sample tube with and without a known specimen. The volume of the known specimen was established by physical measurement or by weight and density measurements. The procedure was to admit $\mathrm{N}_{2}$ gas from a gas bottle (6) to a standard, measured pressure (75.0 psig) according to the Bourdon pressure gage (3). The empty sample tube was sealed under this pressure by closing the isolation valves (2). The gas buret (4) was adjusted to 0 volume at one atmosphere with the level reservoir (5) at the same level as the buret miniscus. The isolation valve leading to the buret was opened and the volume of the gas in the buret tube expanded and displaced the level in the buret. Again the level reservoir was aligned, and the displaced volume was measured and recorded. A standard specimen was placed in the sample tube and the process repeated. The two displacement measurements were used to calculate the sample tube volume. Measurement of different size standards confirmed the sample tube volume.

A weighed sample of microspheres either whole or pulverized was placed in the sample tube. The unknown specimens volume was calculated from the pyconometer measurements using the known sample tube volume. Thus microsphere particle and glass densities were measured.

5.1.4 Pressure Measurements - High pressures in the small fill vessels were measured with a Bourns Model 2900 solid state pressure transducer (range to 20,000 psi). The transducer's output was read with a millivolt digital voltmeter (Figure 7 ) and translated into pressure. Bourdon gauges (Figures 2 and 3) were used for both vacuum (not shown) and manifold pressures up to 20,000 psi. Periodically, the high pressure Bourdon gauge was used to check the pressure transducer.

5.1.5 Microscopic Analyses - The size, shape, and general appearance of each microsphere grade was examined under a standard metallurgical microscope equipped with a camera attachment. The exterior diameters of the individual microspheres were measured with the Filar eye piece attachment. Size distributions were indicated by measuring the largest and smallest microsphere seen on a sample mounted on a microsphere slide. Some samples of microspheres were difficult to distribute in a layer one microsphere deep over the slide without clumping or losing some of the larger spheres. 'A 
drop of alcohol on the microscope specimen wetted the clumps and spread the microspheres on the slide. After drying, the microspheres were examined.

5.1.6 Hydrogen Flow Measurements - Hydrogen flow was measured using a Hastings Flowmeter/Totalizer, range $0-5 \mathrm{ccm}$, model TNALL-5P, Teledyne Hastings-Raydist, Hampton, Va.. The output voltage of the flowmeter (9) shown in Figure 7 , was monitored on a strip chart recorder(10), and indicated on the meter (9). The total volume of hydrogen evolved from the microspheres during dispension was collected and measured in a gas buret (4) at timed intervals which provided a check on the flow rate. The Flowmeter/Totalizer total volume reading was often below the buret reading because the flow instrument was unable to record values that exceed a flow of $5 \mathrm{sccm}$ and its response time was too slow to record bursts accurately. The difference between the totalizer and buret was usually less than $10 \%$. The flowmeter was sensitive to changes in hydrogen flow caused by microsphere breakage during dispension. The oscillations were observed on the strip chart recordings. This and audible popping sounds were used to ascertain when breakage was occurring.

5.1.7 Chemical Analyses - Chemical analyses of glass microsphere grades for the metal content was done by the American Testing Institute, San Diego, California using atomic absorption methods. These values were normalized and converted to the oxide composition and expressed in both weight percent and mole percent.

5.1.8 Crush Test - Prior to crush tests, newly acquired microspheres were subjected to sink-float tests to ascertain the weight fraction of whole microspheres. Cleaned beds of whole microspheres were exposed to nitrogen, hydrogen, and helium at pressures up to $12,000 \mathrm{psig}$ in the small fill vessel shown in Figure 8 described in section 5.1.9. No heat was supplied to the tube. Duplicate samples were measured and each sample was subjected to as many as three pressurization cycles. After the crush test, the sample was sink-floated in isopropyl alcohol to determine the weight percent survivors.

5.1.9 Hydrogen Filling Operation - A sample microsphere bed was loaded into small fill tube (Figure 8 ) and connected to the same manifold used in large scale filling operations. The small fill tubes were also used for dispense tests on small microsphere samples for the screening tests. The small fill tube, shown in Figure 8 , was fabricated from 316 stainless steel bar stock and measures $3 / 8$ in. ID by $3 / 16$ in. wall by $10 \mathrm{in}$. long. A porous stainless steel metal frit was press fitted into the ferrel seal to confine the microsphere charge in the tube. Temperature was sensed by an Iron-Constantan thermocouple placed in a well, machined into the 1 in. thick metal bottom. A heater wrapping was wound around the tube to supply heat. After the heater and thermocouple were attached, the fill tube was evacuated as it was heated to the prescribed fill temperature, usually $350^{\circ} \mathrm{C}$. When the temperature was stablized, the fill tube was pressurized with hydrogen to 3000 psig using the gas compressor purchased for this program. Temperature and pressure in the tube were maintained for $1.0 \mathrm{hr}$. After which, the pressure was, increased to 6000 psig for $1.0 \mathrm{hr}$. and then to $9000 \mathrm{psig}$ for another $1.0 \mathrm{hr}$. Finally, the tube was pressurized to $\$ 12,000 \mathrm{psig}$ and held there for $3.0 \mathrm{hr}$. This was the procedure used for the 400 at $\mathrm{m}$. room temperature filling operation. Lower pressure fillings were accomplished by halting the procedure at the suitable pressure level and maintaining it at that level for 3 hours. 
Tubes were allowed to cool under pressure. If the microspheres were to be retrieved for storage, the tubes were vented in place, disconnected from the manifold, and the filled microspheres transfered to an appropriate storage vessel. Some fill-dispense test specimens were not withdrawn from the fill tube before dispension. In these cases, the pressurized small fill tubes were sealed under pressure by means of their isolation valves (Figure 2). The assembly was disconnected from the gas manifold and connected to the dispense apparatus as shown in Figure 7. The temperature of the tube was reduced to room temperature or, in some cases, to dry ice $\left(-77^{\circ} \mathrm{C}\right)$ temperatures in a dry ice pack. At the low temperatures, both the hydrogen permeability through the microsphere walls and the hydrogen pressure within the microspheres were reduced in preparation for proceeding with dispension tests.

5.1.10 Hydrogen Dispensing Test - Figure 7 shows the dispensing apparatus which consisted of a gas buret (4), a sample fill-dispense tube fitted with a heater and a thermocouple.(1), a temperature controller (10), a flowmeter (9), and a strip-chart recorder (8), as indicated in the figure.

The sample fill-dispense tube (1) was vented, to adjust the internal pressure to 1 atm. of hydrogen, the isolation valve (2) was opened to the buret-flowmeter system. Dispension of hydrogen from the sample tube was controlled by heating the sample tube. The sample tube temperature was. sensed by an Iron-Constantan thermocouple located in a thermocouple well machined into the 1 inch thick bottom of the tube. A Barber Colman Model 580 Controller (10) was used to control the tube temperature. The temperature was increased in steps up to $400^{\circ} \mathrm{C}$ and held steady at each level unt il the hydrogen flow rate decreased to $<0.5 \mathrm{ccm}$. In general, the thermal steps were $25^{\circ} \mathrm{C}$, starting at room temperature. The dispensed hydrogen gas flowed through a flow meter detector located behind the buret and registered on a flow meter (9). Hydrogen was accumulated and measured by liquid displacement in the gas buret. Flow rates, total flow as measured by the flow meter, and buret readings were recorded in laboratory records as a function of time. When dispension was completed, the sample tube was cooled to room temperature, and the sample removed, re-weighed, and subjected to a sink-float analysis to determine the weight percent survivors. The separated survivors were then submitted to particle density measurement.

The above procedure provided for quantitative measurement of hydrogen gas escaping during the dispension cycles. The gas volume permeating out of the microsphere bed below room temperature was. measured. Hydrogen flow oscillations and audible breakage were noted and correlated to the test conditions at any stage in the dispension cycle.

\subsection{DATA EVALUATION}

Formulas used, last year, to relate measured parameters to basic microsphere bed characteristics were reviewed. The earlier equations assumed that the microsphere wall volume was a negligible fraction of the microsphere volume. This simplifying assumption was not valid. Errors of 10-20 per cent were introduced. These errors, in part, accounted for some of the difficulties in establishing hydrogen accountability for the experimental results reported last year. All the relations have been revised; and the new formulas, given below, were used for evaluating the fill-dispense data appearing in this report. 

$A=\frac{2}{1-\left(1-\frac{\rho_{p}}{\rho_{g} l}\right)^{0.339}}$
Equation 1
$d=\frac{6}{\rho_{p} S}$
Equation 2
$w=\frac{3\left[1-\left(1-\frac{\rho_{p}}{\rho_{g} \mid}\right)^{0.333}\right]}{\rho_{p} S}$
Equation 3

Where, $A$ is the average aspect ratio (diameter/wall thickess), $\rho_{p}$ is the average particle density $(\mathrm{g} / \mathrm{cc}),{ }^{\circ} \mathrm{gl}$ is the average microsphere $\mathrm{glass}$ density $(\mathrm{g} / \mathrm{cc})$, $d$ is the average particle diameter $(\mu \mathrm{m}), S$ is the surface area per bed weight $\left(\mathrm{m}^{2} / \mathrm{g}\right)$, and $w$ is the average microsphere wall thickness $(\mu \mathrm{m})$.

The maximum hydrogen weight density $\left(\boldsymbol{m a x} . \mathbf{D}_{\mathbf{w}}\right.$ ) was calculated from the fill conditions and bed characteristics as follows:

$\max : D_{w}=\frac{f_{w} P_{f}\left(1-\frac{\rho_{p}}{\rho_{f} \rho g l}\right)}{T_{f} \rho_{p}}$

Equation 4

Where $P_{f}$ is the fill pressure (atm) at the fill temperature, $T_{f}\left({ }^{\circ} \mathrm{K}\right), Z_{f}$ is the hydrogen gas compressibility factor under the fill conditions, $\mathbf{f}_{\mathbf{w}}$ is the fraction of whole microspheres (wt \%) and $R$ is the gas constant in consistant units (40.7).

The compressibility, $\mathbf{Z}_{\mathbf{f}}$, was calculated from equations given in last year's progress report. ${ }^{(2)}$

$$
Z_{350}=1.00+3.00 \times 10^{-4} \mathrm{P} \quad \text { Equation } 5
$$

Where, $Z_{350}$ is the compressability factor at $350^{\circ} \mathrm{C}$ and $P$ is the absolute hydrogen gas fill pressure (atm.)

The measured hydrogen weight density, $D_{w}$, was calculated as follows: 


$$
D_{w}=\left(8.18 \times 10^{-5}\right) \frac{V_{h}}{W_{s}}
$$

Where, $V_{h}$ is the volume of released hydrogen during dispension measured at STP $(c c), W_{s}$ is the weight of the specimen $(g)$, and, $8.18 \times 10^{-5}$ is the density of hydrogen under $\operatorname{STP}(\mathrm{g} / \mathrm{cc})$

\subsection{Test Results}

The results of screening tests are reported in Table 2. In order to avoid sampling uncertainties, the same specimen was used in as many tests as possible. Fortunately, most of the tests employed were non-distructive.

5.3.1 Chemical Analyses - The results of the chemical analysis of the eight candidate microsphere grades are summarized in Table 3. All results are averages of duplicate samples and duplicate tests on each sample. They were adjusted for oxygen assuming the oxide formulas given in the table and normalized to give weight and molar concentrations.

The $3 \mathrm{M}$ grades appear to be made of lime-soda-boro-silicate glass compositions. Emerson and Cuming grades are made of sodium-boro-silicate compositions. Fillite "flyash" grades are made of an alumino-silicate glass. The iron oxide in the latter grade is present predominately as a separate phase inclusion. The mole percent glass non-network glass formers for each grade was calculated by adding the compositions of all glass constituents except $\mathrm{SiO}_{2}$ and $\mathrm{B}_{2} \mathrm{O}_{3}$. The glass composition implies other well established glass properties: softening point, anneal temperature range, general strength and hygroscopic behavior. Mole percent non-network glass formers ranged from 5 to 25 , as shown in the last column in Table 3.

The relationship of composition to hydrogen permeability (k) obtained from the literature in 1978 is given in Equation $7 .(3)$

$$
k=2.947 \times 10^{-11}\left[3.4+\left(8 \times 10^{-4}\right) M^{3}\right] T \exp -\frac{3600+165 M}{T} \quad \text { Equation } 7
$$

Where, $\mathbf{T}$ is the temperature $\left({ }^{\circ} \mathrm{K}\right), \mathbf{M}$ is the mole percent non-network glass formers and $k$ is the permeability [cc $H_{2}$ (STP) $\mathrm{mm} / \mathrm{sec} \mathrm{cm}^{2}\left(\mathrm{~cm} \mathrm{of} \mathrm{H}_{g}\right)$.

Using the non-network glass former concentrations (Table 2) and Equation 7 , commercial microspheres can have hydrogen permeabilities ranging from $4.22 \times 10^{-12}$ to $1.79 \times 10^{-14}$ (over two orders of magnitude) at $200^{\circ} \mathrm{C}$. This illustrates the importance of glass composition in the selection of microsphere grades for microcavity hydrogen storage applications

5.3.2 Particle Dimensional Analyses - Prior to particle physical measurements, the whole microspheres of each grade were separated and washed in an iso-propyl alcohol sink-float operation. Average microsphere diameters and wall thicknesses were calculated from measured bed properties: average particle density, average glass wall density and particle surface area, using equations 1,2 and 3. The measured values were checked in duplicate and triplicate analyses on the same or on separate samples. Samples of each 
grade were crushed in high pressure nitrogen gas to obtain a microsphere glass sample for chemical analysis and glass density measurements. Specimens of cleaned, whole microspheres were subjected to gas pycnometer particle density measurements. The same specimen was also used to obtain area measurements. Smaller samples of the cleaned microspheres were submitted to microscopic examination as discussed in Section 5.3.4.

5.3.3 Density Measurements - Class densities for the candidate microsphere grades varied from 2.1 to $2.3 \mathrm{~g}$. per cc. Vendor information indicated that the density should be 2.5 g. per cc. Microscopic examination of some of the density specimens revealed entrained whole microspheres in the shards. The whole microspheres trapped in the shards were detected by placing a sample of shards on a microscope slide and applying a drop of oil used for oil immersion microscope lenses. Whole microspheres appear as bubbles and the broken microsphere fragments were transparent. Although the glass density measurements had been made, it was decided to use 2.5 g. per cc. for all glass densities. A more serious problem was the entrainment of broken microsphere fragments with whole microspheres thus increasing the particle density analysis results. Microscopic examination was used to detect the problem. A remedy for both of the above problems was to repeat the sink-float operation if the cross contamination was high.

Average particle densities, glass densities and bed area measurements for the eight candidate grades and 3M-D32/4500 Lot P5427-1 are assembled in Table 2. These results will be discussed further in Section 5.3.6.

5.3.4 Microscopic Analyses - Table 4 gives the measurements for the largest and smallest microsphere detected under the microscope for the eight grades before and after a 6000 psig nitrogen crush test. A discription of the general appearance of the microspheres is also given. In nearly all cases, the size distribution was apparently shifted to lower sizes which indicated that the largest microspheres have a lower strength. In general, all the grades had a similar particle size distribution but the average ( $T$ able 4) varied.

Figures 9, 10, 11 and 12 show typical photomicrographs of the eight candidate microsphere grades at $157 x$ magnification. Nearly all the grades have some dark specks on the microsphere surface,. The surface of grade $3 M-B 38 / 4000$ was especially dirty with debris clinging to the microspheres. Some microspheres of the rillite $200 / 7$ grade were very dark, opaque and had large iron oxide inclusions in the microsphere wall. The microsphere walls of the remaining six grades were clear and transparent. i hese photomicrographs show the variation in size among the eight grades of microspheres; which was expected since they were produced commercially for use as light weight fillers for epoxys.

5.3.5 Crush Test Results - Table 5 presents the results of the crush test studies. The microsphere samples were tested in nitrogen, hydrogen, and helium at 5500 to 6000 psig. The reported results have been obtained on duplicate samples with each sample cycled as many as three times to the same crush pressure. Agreement between tests on the same grade and crush pressure were within a few percent. Variations in crush pressure, from 5500 to $6000 \mathrm{psi}$, as indicated in the table, do not affect the results appreciably as varified in other unreported tests. Aside from the variation in crush strength from grade to grade, the pressurizing gas composition contributed a significant effect. For example, crush tests on $3 M-D 32 / 4500$ grade resulted in 54 wt \% survivors in nitrogen, $88 \mathrm{wt} \%$ in hydrogen and $75 \mathrm{wt} \%$ in helium. Similar trends were found for the other grades. An explanation of this phenomenon is not available without more study. 
Crush strengths of the two lots of $3 M-D 32 / 4500$ and their heat treated samples were also included in Table 2. The onset of sintering limited the temperature of the annealing treatment for lot $\mathrm{D} 1516-6$ to $500^{\circ} \mathrm{C}$. Consequently, the improvement brought about by heat treatment on this lot of microspheres was not appreciable. As noted in the table, the bracketed results were corrected for the debris in the "as received" microspheres. These crush test results will be discussed further in Section 5.3.6.

5.3.6 Screening Test Results - Screening test results are summarized in Table 2 including the mole percent of non-network formers derived from the chemical analyses (Table 3), calculated dimensional averages, and crush strengths (Table 5). Wide variations in particle dimensions, chemical compositions and strengths available from cornmercial grades of microspheres were apparent.

Specimens from each of the eight grades were crushed in a 5500 psig nitrogen atmosphere and the survivor microspheres analyzed for average particle dimensions. In nearly all cases, the crush survivors have a lower aspect ratio (diameter to wall thickness) than the "as received" microspheres. This was to be expected since the lower aspect ratio (heavier wall) microspheres should be stronger. At the same time, the average diameter increased in some grades and diminished in others with no apparent correlation to survivor count. The average aspect ratio for crush survivors ranged from 25 to 45. Fillite $200 / 7$ and EC-HASY in the "as received" condition have the lowest aspect ratio values and would be expected to be strong. Microscopic studies last year indicated that failure in the Fillite grade was not caused by glass strength limitations but by the presence of $\mathrm{FeO}$ inclusions or chemical non-uniformity in the microsphere walls. The EC HASY grade was very strong ( $92 \%$ survivors in a 5500 psig nitrogen crush). Its average aspect ratio was already lower than the crush survivors of the other grades.

Microsphere breakage in the crush test is probably induced by a compressive, buckling mode while the failure mode for the filled microspheres was mainly tensile. However, it was thought that crush tests would provide some indication of the relative microsphere strength which ultimately limits the maximum possible hydrogen storage weight density. An extrapolation of this relationship to 100 per cent survivors indicated an average aspect ratio for survivors should be less than 30-40.

A significant observation from the crush test experimental data was that the Emerson \& Cuming and $3 \mathrm{M}$ grades test results both gave about the same crush testsurvivor aspect ratio, even though the grades have widely divergent chemical compositions and were fabricated by different manufacturing processes. Measured average aspect ratios of surviving microspheres after a 5500 psi crush (Table 5) were in the range of 36 to 46 exclusive of that for Fillite 200/.7 and E \& C-HASY.

Another result of the crush study is that it indicated that crush treatments, when applied to commercially available microspheres, help produce a product having sufficient strength to withstand a 400 at $\mathrm{m}$. fill-dispense cycle without excessive breakage.

5.3.7 Fill-Dispense Tests - Fill-Dispense test results (Table 6) provided the most significant evaluation of microsphere beds. Breakage, expressed as weight percent survivors, hydrogen weight density, the hydrogen availability at a minimum flow rate of $\backsim 0.5$ sccm and the hydrogen volume density were considered the most significant bed performance characteristics. Data on the physical parameters of sample beds (Table 2) were used to determine the maximum hydrogen weight density. The maximum bed hydrogen weight density was calculated (Equation 4) using the gas storage volume within 
the microspheres and the calculated hydrogen gas density under fill conditions, using well known compressibility data available from the literature, and the specimen weight. The measured total average hydrogen weight density of the bed $\left(D_{w}\right.$ total) was derived from gas dispensed both below and above room temperature from a weighed bed. If it compared favorably to the maximum hydrogen weight density, the data was considered valid.

The average pressure within the microspheres at any point in the dispense cycle could be estimated from the hydrogen released to that point in the dispense cycle provided no appreciable breakage occurred at the same time. When breakage occurs during the dispense cycle, the interpretation of data is more complex. There was no direct method for measuring the hydrogen permeation through the microsphere walls independent of that released by breakage. Last year, fill pressures were reduced to avoid breakage. This year, all of the "off the shelf" commercial microspheres grades exhibited some breakage under standardized 300 at $\mathrm{m}$. fill conditions and considerably more under standardized 400 atm. fill conditions. The dispension properties are considered to be "first cycle" properties only.

No experimental measurements of the hydrogen volume density were made since this term was sensitive to the hardling procedures employed during the loading of the microsphere bed. The hydrogen volume density was estimated by assuming a packing fraction of 65 percent and a hydrogen gas density within the microspheres, which was deduced from the fill conditions and the measured weight percent whole microspheres in the "as received" microspheres. Grades $3 M-D 32 / 4500$ and E\&C HAS were clean products therefore the weight percent whole microsphere was considered to be $\sim 1$. Hydrogen volume densities of $\backsim 0.0134 \mathrm{gm} \mathrm{H}$ per $c c$ of bed at a 300 at $\mathrm{m}$. room temperature fill pressure and a density of $0.0169 \mathrm{gm} \mathrm{H}_{2}$ per $\mathrm{cc}$ of bed for a 400 atin. fill were estimated regardless of microsphere grade.

Breakage should not have a large effect on the hydrogen volume density. A packing fraction of $\backsim 0.65$ means that 35 percent of the bed volume is available for accommodating the broken microsphere fragments. Breakage of 20 to $30 \mathrm{wt}$. percent of the bed should fit in between microspheres and have essentially little effect on the hydrogen volume density. Hydrogen weight density measurements were directly affected by breakage. Concurrent breakage during hydrogen dispension would affected the interpretation of hydrogen availability information also. The level of breakage detected in most of the tests was intolerable if it occurred upon each fill-dispense cycle of the microsphere in a practical application. It is anticipated that the broken microspheres may be removed after the first cycle and the surviving whole microspheres would break less readily or cease to break in subsequent cycles.

In the course of performing fill-dispense tests, breakage was detected by noting hydrogen flow variations and audible popping. Breakage was detected in several parts of the fill-dispense cycle: pressurization during filling; depressurization at low temperature; during the early stages of heating for dispension; and, handling. Breakage during the filling operation was minimized by filling the bed in pressure steps, thus restricting the maximum compressive pressure on the microspheres to less than 3000 psi, a pressure that most of the microsphere grades did withstand. Breakage during depressurization was minimized by lowering the teinperature of the bed. Cooling the bed to dry ice temperature for the depressurization operation not only depressed hydrogen permeation, but it lowered the gas pressure inside the microspheres as well. The cooling operation also 
allowed sufficient time to attach the fill vessel to the dispension apparatus measuring equipment and to adjust the gas pressure in the dispension rig to one at $\mathrm{m}$. This procedure also assured the measurment of the total hydrogen weight density which was used to validate that the microsphere bed was filled initially. Some grades may have required a lower depressurization temperature to survive the operation. No attempt was made to measure this effect or optimize the conditions. Since practically all the hydrogen was accounted for in the tests, this breakage must have been low.

Microsphere breakage was detected as the temperature was increased from the depressurization teinperature. In some grades, the breakage was accompanied by permeation. The quantitative relationship of the two hydrogen release mechanisms would vary with the characteristics of the particular microsphere grade; but could not be measured separately. Breakage due to handling was minimal.

Total breakage was measured after the test and the volume of gas released during periods of maximum breakage were noted. For example, $3 \mathrm{M}$ grade D32/4500 did not exhibit very much breakage between dry ice temperature and room temperature. Dispense data indicated that about $90 \%$ of the microspheres survived the filling and reheating to room temperature. Most microsphere breakage occured between room temperature and $170^{\circ} \mathrm{C}$.

A's planned, the eight candidate microsphere grades and the original lot of $3 \mathrm{M}$ D 32/4500 were subjected to standard fill-dispense cycles at 300 and 400 at $\mathrm{m}$. fill levels. These results are summarized in Table 6.

The agreement between the calculated maximum hydrogen weight density $\left(D_{w}\right.$ max.) and the measured total hydrogen weight density ( $D_{W}$ total) was reasonably close (above $80 \%$ ) in most tests. Some of this discrepency could be due to the breakage occurring as the fill vessel was depressurized, and before it could be attached to the dispense system. The discrepency did appear to be greatest when the overall breakage was greatest.

Emerson \& Cuming grades $\mathrm{Sl}$ and 202, and, Fillite grade 200/7 have a survival less than 26 percent under 300 atm. fill-dispense conditions. The rest of the microspheres (rated in order of increasing survivor percentile) are: $3 M-B 38 / 4000, E \& C H A S, 3 M-$ A 38/4000, 3M D32/4500 (lot P5427-1), E\&C HASY and 3M-D32/4500 (lot D1516-6). In addition, two lots of $3 M-D 32 / 4500$ and Emerson \& Cuming grades HAS and HASY were also evaluated under $400 \mathrm{~atm}$. conditions. The measured percent survivor values were low, between 30 and 57 percent, respectively. With the high level of microsphere breakage encountered in fill-dispense tests on all commercial microsphere grades, the filldispense results (Table 6 ) represent only the first cycle characteristics.

Fill-dispense results for $3 M-D 32 / 4500$ and $E \& C$ HAS under 300 atm. fill conditions were the most significant since these grades had the lowest breakage. In general, the Emerson \& Cuming grades exhibit a high permeability because of the glass composition. Consequently, the hydrogen availability from these beds was high. Correspondingly, it is anticipated that the storage life will be low. The $3 M-D 32 / 4500$ has a lower permeability and, according to storage life studies conducted last year, has a reasonable storage life. The Emerson \& Cuming grade was found to have a low average hydrogen weight density because of its lower average aspect ratio. The average aspect ratios of the $3 \mathrm{M}$ grade survivors from the fill-dispense tests were higher (lower particle density, Table 6), indicating that the glass used in the $3 M$ microspheres was apparently stronger than that used 
in the Emerson \& Cuming microspheres. The hydrogen volume density of the Emerson \& Cuming grade is likely to be slightly lower than that of the $3 \mathrm{M}$ grade because of its lower aspect ratio.

The observed hydrogen availability results were in qualitative agreement with those expected from the non-network former glass concentrations reported in Table 3.

it is obvious from the reported results that "as received" commercial microsphere grades do not perform well for $400 \mathrm{at}$. hydrogen storage beds. The average aspect ratio of the bed must be decreased from that now available to hold higher internal pressures. Microsphere glass compositions should be adjusted to an estimated non-network former glass composition of 9-10 for an automotive application to improve hydrogen availability. (1)

Average fill-dispense survivor particle densities of the candidate grades filled to $300 \mathrm{~atm} . \mathrm{H}_{2}$ storage pressure, reported in Table 6, were higher than their corresponding "as received" particle density given in Table 2. The fill-dispense survivor particle densities were about the same as that of the 5500 psi $N_{2}$ crush treatment. At first glance, it may be concluded that the microspheres can withstand a crush pressure and an internal pressure equally well. However, during the dispense cycle test at temperatures above room temperature, the internal microsphere pressure, initially at $6000 \mathrm{psi}$ at room temperatures, may rise to 11,000 psi before permeation commences. Consequently, the microspheres do withst and a higher internal pressure.

On the basis of the above experimental screening test program results, $3 M-$ D32/4500 and E\&C HAS grades were selected for improvement and cyclic testing studies which were to be conducted in Tasks 4 , and 6 .

\subsection{MIC ROSPHERE MODIFICATION (TASK 4)}

All the experimental data collected last year was reviewed and up-dated to suppliment and substantiate the conclusions of this program. Table 7 summarizes the revised data on the fill-dispense tests reported in 1979. The close agreement of the measured total hydrogen weight density and the calculated maximum hydrogen weight density confirmed that a hydrogen balance had been achieved. I he new values did not change the conclusions drawn in the previous study. The average hydrogen weight densities were slightly higher than those measured this year on the new $3 M-D 32 / 4500$ grade. The hydrogen volume density was low because of the low fill gas pressure.

One of the objectives of Task 4 was to examine particle density (aspect ratio) trends to develop specifications for microsphere beds that will retain hydrogen at pressures greater than $400 \mathrm{~atm}$ and be dispensed without breakage.

Preliminary information for the microsphere modification studies were obtained during the screening tests (Section 5.3.6). Aspect ratios of microsphere beds before and after a 5500 psig nitrogen crush test were measured. In all cases, except Fillite 200/7, the aspect ratio decreased indicating that microspheres with thin walls fail first as would be expected. More evidence for this trend was found during crush tests conducted at pressures up to $12,000 \mathrm{psig}$ nitrogen (Figures 13 and 14). The average particle density was monitored. Although time did not permit this series of tests being repeated for hydrogen atmospheres, it would likely have shown a similar trend but at the higher microsphere strengths found in the 5500 psig crush tests. 
Fill-dispense test survivors were also monitored. Survivors of fill-dispense tests at $300 \mathrm{~atm}$. (Table 6) had average particle densities of 0.30 to $0.35 \mathrm{~g} / \mathrm{cc}$ which corresponds to an average aspect ratio range of 40-48. Survivors to $400 \mathrm{~atm}$ fills had average particle densities between 0.35 and $0.42 \mathrm{~g} / \mathrm{cc}$ (aspect ratios of 34-40). There was not enough information to establish a precise failure threshold. In any event, it would be difficult to establish a well defined threshold because the values presented were for microsphere bed averages and not individual microspheres. Microspheres having particle densities higher than the strength threshold would survive the test. Depending upon their concentration and the particle aspect ratio distribution breadth, they would lower the measured average aspect ratio of the bed below the true threshold value. As a result of the experimental data review, a particle density goal of 0.35 to $0.42 \mathrm{~g} / \mathrm{cc}$ was considered a starting point for the modified microsphere grade studies.

A series of crush treatments from 6000 to 12,000 psi were performed on $3 \mathrm{M}$ D32/4500 Lot 1516-6 and Emerson and Cuming grades HAS and HASY. These results are shown in Figures 13 and 14 . In all grades, the particle density was higher (aspect ratio decreased) at higher nitrogen crush pressures. The numbers in the circles indicate survivor percent of cleaned "as received" microspheres. The particle density goal (0.35-0.42 $\mathrm{g} / \mathrm{cc}$ ) was reached for $3 M-D 32 / 4500$ and $E \& C$ HAS grades. E\&C HASY exceeded the requirement in the "as received" condition.

A preliminary study of particle size improvements was conducted by a particle density survey on size fractions of $3 M D 32 / 4500$ and of the two Emerson \& Cuming grades HAS and HASY. The results are summarized in Table 8 . In all cases, the particle density was higher for the smaller particle size fraction. These results suggest that particle size separations can also be used to adjust the particle density and may lead to improved bed fill-dispense performance. Again the particle density goal was reached.

It can be concluded from the data presented above, that the prograin was corning to a point where specifications of an ideal microsphere bed could be defined. By suitable treatments of commercial grades, a suitable microsphere grade could be separated to meet the needs of several hydrogen storage applications.

From the tests conducted this year, it appears that the apparent strength of commercial microsphere beds is a limitation to the fill pressure. The apparent tensile strength of glass in commercial microsphere grades has been estimated at $\sim 50-75,000$ psi. This value is an apparent strength because the evaluation takes into account wall variations, aspect ratio variations, glass composition variations and other microsphere bed imperfections. Data in the literature indicate that glass in the form of fibers having diameters of the order of microsphere wall thicknesses, have strengths above 300,000 psi. Therefore there is room for the improvement of glass wall strengths.

The hydrogen permeation characteristics of microsphere beds are controlled by the microsphere glass composition. This appears to be almost independent of the attainable microsphere strength. Both were influenced by thermal treatments. Time did not permit studies on thermal treatments other than that reported in Section 4.0.

No chemical treatments were evaluated. 


\subsection{DISCUSSION}

The reported survey of commercial grades of microspheres made it apparent that the "off the shelf" microspheres did not fulfill all the requirements for high density hydrogen storage. In particular, they could not withstand the internal gas pressures created during hydrogen dispension. Breakage was the greatest concern. RJTA started to investigate the strength of microspheres using particle density as a guide. Some preliminary measurements of average particle density on commercial grades after crush treatments and particle size separations were providing quantitative information for guiding a fill-dispense test investigation. Since the study was not completed, specific specifications cannot be formulated at this time. However, starting points for future studies are apparent.

No specific applications were delineated in this program. However, three principal applications can be discussed: automotive applications, long-term stationary hydrogen storage and hydrogen separation from gaseous mixtures. The primary selection must be made on the basis of hydrogen permeability characteristics. Apparently, these characteristics are essentially independent of other considerations; strength, fabricability, dimensional and probable cost.

Automotive applications require permeability control. The storage life must be balanced with fuel recovery rate. In the 1978 study, it was determined, from what permeability information was available, at that time, and available microsphere dimensions, a nine mole percent non-network glass former composition would be desired. The microsphere grade closest to meeting this application requirement was $3 M-D 32 / 4500$ grade with thirteen mole percent. As expected, the measured hydrogen availability for this grade was slightly lower than desired.

Long term hydrogen storage requires a high non-network glass former concentration. This requirement can be met by either $3 M-D 32 / 4500$ with its 13 percent non-network glass former composition or $3 \mathrm{M}-\mathrm{A} 38 / 4000$ with its 15 percent non-network glass former concentration.

Separation of hydrogen from gas inixtures require a high permeation rate. Emerson \& Cuming grades have the necessary lower non-network glass former concentrations to meet these requirements.

Strength requirements for the three applications need to be defined in more detail. For example, automotive and long term storage will require high strength microspheres to obtain high hydrogen volume densities while gas separations may not.

In the tests performed on microsphere bed samples, each microsphere is tested almost independently. The fact that some survive a 400 at in fill-dispense test means that some fraction of the commercial microspheres meet the needs for microcavity hydrogen storage. The problem is to devise a process to selectively concentrate or directly produce microspheres with the desireable properties. A systematic investigation should be undertaken to define the properties of the desireable microsheres and then ask the manufacturers to modify their processes to produce them. 


\subsection{CONCLUSIONS*}

The most significant conclusions drawn from this experimental study are:

1. It has been confirmed that large microsphere beds have the same hydrogen storage and dispension characteristics as small samples used in laboratory tests.

2. Two cu. ft. of hydrogen filled microsphere beds have been produced with reasonable reproducibility. They were handled, packaged and shipped to BNL without appreciable loss of hydrogen.

3. None of the commercially available, "off the shelf", microspheres can be used under fill-dispense cycles for 400 atm. room temperature hydrogen storage without breakage on the first fill-dispense cycle.

4. Although the microsphere strength requirement may be met, the dispension characteristics of candidate grades for automotive applications will need improvement by adjusting the glass composition.

5. A fill-dispense test data survey indicated that microsphere beds having average particle densities in the range of 0.35 to $0.40 \mathrm{~g}$ per cc are good candidates for storing hydrogen at pressures up to 400 at $\mathrm{m}$.

6. Some preliminary studies on crush treatments and particle size separations indicated that the desired particle densities may be extracted from commercial grade microspheres.

7. A new source of high strength microspheres with high hydrogen permeability was found in the Emerson \& Cuming grades HAS and HASY.

8. The crush strength of microspheres depends upon the chemistry of the atmosphere. Microspheres appear to be stronger in hydrogen than in either helium or nitrogen.

9. Although the commercial "off-the-shelf" grades of microspheres are not satisfactory, some of the microspheres were filled and dispensed to a storage pressure of 400 atm; thus establishing that the microsphere storage concept is feasible.

\subsection{RECOMMENDATIONS}

RJTA makes the following recommendations for the future development of microspheres for microcavity storage systems.

1. The application objectives should be defined individually and relative priorities be est ablished.

2. Technological goals should be set as to what technology is needed in what time frame for each application and programs established for each application.

3. The systematic search for finding microspheres established in the current program should be continued: (1) Define hydrogen permeability requirements by studies on each application (automotive, stationary storage, and hydrogen separation) similar to those conducted in 1978 for the automotive application; (2) Using the relationship of permeability to chemical composition, select microsphere products with compositions close to that desired for each application; (3) Extract a portion of commercial microspheres having the practical mechanical properties needed in each application; (4) Establish microsphere bed specifications for each application; (5) Submit specifications to microsphere manufacturer for supply and cost evaluations; (6) Up-date microcavity systems application studies conducted in (1) above using experimental

*Also see Addendum to Conclusions following Reference Section. 
information and update its comparison to other alternative systems; (7) accurate estimations should be made of the total storage costs including material cost, operating (energy) costs and capital costs.

4. Experimental techniques and tests for evaluating microsphere beds should continue to be developed and automated.

5. A mathematical model for gas dispension should be developed and computer programed, using the flow equations derived in the 1978-1979 program.

6. Small and large scale demonstrations of the various applications should be planned in time to meet application needs.

\section{ACKNOWLEDCEMENTS}

The author wishes to acknowledge the efforts of J. E. Niemeyer and K. Koyama in the laboratory and F. E. Teitel for report preparation.

\section{REFERENCES}

1. R. J. Teitel, T. M. Henderson et al, Microcavity Systems for Automotive Applications, Final Progress Report, RJTA Report No. 780001006U-R2, November 21, (1978)

2. R. J. Teitel, et al, Microcavity Systems for Automotive Applications, Final Progress Report, RJTA Report No. 79-7, December 31, (1979)

3. J. E. Shelby, Compositional Dependency of the Permeability of Glass, Sandia Laboratory-Livermore Report SCL-RR-70-8, (1970)

\section{ADDENDUM TO CONCLUSIONS \\ BY BNL PROJECT MANAGEMENT STAFF}

The use of commerclal grade hollow-glass microspheres for high pressure hydrogen storage has been shown to be cost ineffective. The major factors that impact storage costs are: the initial material cost, the breakage due to fill/ release cycling, the hydrogen storage density, the recoverable hydrogen fraction, and the energy intensiveness of the filling and release process.

- The material cost, originally estimated to be on the order of $10 \notin$ per pound, has been quoted by two manufacturers to be between $\$ 1.00$ and. $\$ 1.75$ per pound.

- Microspheres are fragile and breakage as a result of filling and dispensing hydrogen can be appreciable. Differential pressures across the thin glass wall, whether high internally or externally, tend to break the microsphere. Loss or breakage as low as $1 \%$ per cycle is not cost effective.

- The results of the experimental effort is that commercially available microspheres can usefully store less than $5 \%$ hydrogen by weight instead of the original estimate of $10 \%$.

- Commercial-grade microspheres are not suitable for hydrogen storage, although material customized for that application may fare better. 
The use of commercial grade hollow-glass microspheres for high pressure hydrogen storage has been shown to be cost ineffective. The major factors that impact storage costs are: the initial material cost, the breakage due to fill/ release cycling, the hydrogen storage density, the recoverable hydrogen fraction, and the energy intensiveness of the filling and release process.

- The material cost, originally estimated to be on the order of $10 \notin$ per pound, has been quoted by. two manufacturers to be between $\$ 1.00$ and $\$ 1.75$ per pound.

- Microspheres are fragile and breakage as a result of filling and dispensing hydrogen can be appreciable. Differential pressures across the thin glass wall, whether high internally or externally, tend to break the microsphere. Loss or breakage as low as $1 \%$ per cycle is not cost effective.

- The results of the experimental effort is that commercially available microspheres can usefully store less than $5 \%$ hydrogen by weight instead of the original estimate of $10 \%$.

- Commercial-grade microspheres are not suitable for hydrogen storage, although material customized for.that application may fare better. 
TABLE 1 - LARGE SCALE FILLING STUDY DISPENSE TEST RESULTS (Grade 3M-D32/4500 Lot No. D1516-6) Annealed

\begin{tabular}{|c|c|c|c|c|c|c|c|c|c|c|c|}
\hline RUN & $\begin{array}{l}\mathrm{T}_{\mathrm{a}} \\
\left({ }^{\circ} \mathrm{C}\right)\end{array}$ & $\underset{(\operatorname{at} \mathbf{m})}{P_{f}}$ & $\% 5$ & $\begin{array}{l}D_{W} \\
>R_{T}\end{array}$ & $\begin{array}{l}\% \text { AV } \\
200^{\circ} \mathrm{C}\end{array}$ & $\begin{array}{l}1 \mathrm{LBBL} \\
250^{\circ} \mathrm{C}\end{array}$ & $\begin{array}{l}E \\
300^{\circ} \mathrm{C}\end{array}$ & $\underset{>R_{T}}{V_{w}(c c)}$ & $w_{s}(g)$ & $\underset{\text { Max. }}{D_{w}}$ & $\begin{array}{r}\text { EXP. } \\
\text { NO. }\end{array}$ \\
\hline 2 & 485 & 262 & 76 & 0.0362 & 20 & 43 & 63 & 423 & 0.9558 & 0.0564 & $4-83$ \\
\hline 3 & 500 & 262 & 79 & 0.0413 & 27 & 47 & 68 & 110 & 0.2179 & 0.0564 & $4-40$ \\
\hline 4 & 500 & 262 & 83 & 0.0412 & 37 & 51 & 69 & 106 & 0.2103 & 0.0564 & $4-43$ \\
\hline 6 & 500 & 262 & 83 & 0.0401 & 27 & 47 & 77 & 86 & 0.1753 & 0.0564 & $4-50$ \\
\hline 7 & 500 & 262 & 73 & 0.0448 & 33 & 57 & 95 & 99 & 0.1808 & 0.0564 & $4-57$ \\
\hline 8 & 500 & 262 & 72 & 0.0462 & 36 & 61 & 94 & 100 & 0.1771 & 0.0564 & $4-60$ \\
\hline Average & & 262 & 79 & 0.0418 & 28 & 49 & 77 & & & & \\
\hline
\end{tabular}

\begin{tabular}{llllllllllll}
\hline $\begin{array}{l}\text { Lot } \\
\text { D1516-6 }\end{array}$ & 485 & 262 & 84 & 0.0421 & 29 & 42 & 76 & 155 & 0.3014 & 0.0564 & $4-33$ \\
\hline \hline $\begin{array}{l}\text { Lot } \\
\text { P5427-1 }\end{array}$ & 580 & 296 & 83 & 0.0436 & 34 & 64 & 82 & 404 & 0.7588 & 0.0591 & $4-69$ \\
\hline
\end{tabular}

$\mathbf{P}_{\mathbf{f}}$ - Fill Pressure, $\boldsymbol{\phi} \mathbf{S}-\mathbf{W t}_{\mathbf{t}} \%$ survivors of test, $\mathbf{D}_{\mathbf{w}}$-hydrogen weight density, $\mathbf{V}_{\mathbf{h}}$-volume of hydrogen released at STP, $W_{s}$-weight of specimen.

- annealing temperature

R J T A5217B 
TABLE 2 - SCREENING TEST RESULTS

\begin{tabular}{|c|c|c|c|c|c|c|c|c|}
\hline Grade & $S\left(m^{2} / g\right)$ & ${ }_{p}(g / c c)$ & $\rho_{g}(g / c c)$ & $A *$ & $d^{*}(\mu m)$ & $w *(\mu m)$ & $M=(\%)$ & \% Surv. \\
\hline \multicolumn{9}{|c|}{ D32/4500 (P5427-1) } \\
\hline$A R($ clean) & 0.670 & 0.302 & 2.50 & 47.7 & 29.7 & 0.622 & 13 & \\
\hline $\mathrm{C}-5500\left(\mathrm{~N}_{2}\right)$ & 0.740 & 0.336 & 2.50 & 42.6 & 24.1 & 0.566 & 13 & 56 \\
\hline \multicolumn{9}{|c|}{ D32/4500 (D1516-6) } \\
\hline$A R$ (clean) & 0.475 & 0.288 & 2.50 & 50.1 & 43.9 & 0.876 & 13 & \\
\hline$C-5500\left(N_{2}\right)$ & 0.517 & 0.318 & 2.50 & 45.2 & 36.5 & 0.808 & 13 & 59 \\
\hline \multicolumn{9}{|l|}{ A 38/4000 } \\
\hline AR (clean) & 0.390 & 0.353 & 2.50 & 40.5 & 43.6 & 1.08 & 15 & \\
\hline $\mathrm{C}-5500\left(\mathrm{~N}_{2}\right)$ & 0.276 & 0.400 & 2.50 & 35.5 & 54.4 & 1.538 & 15 & 77 \\
\hline \multicolumn{9}{|l|}{ B 38/4000 } \\
\hline AR (clean) & 1.055 & 0.292 & 2.50 & 49.4 & 19.5 & 0.395 & 15 & \\
\hline$C-5500\left(N_{2}\right)$ & 0.603 & 0.338 & 2.50 & 42.4 & 29.4 & 0.695 & 15 & 44 \\
\hline \multicolumn{9}{|l|}{ Fillite $200 / .7^{2}$} \\
\hline$A R$ (clean) & 0.198 & 0.562 & 2.50 & 24.6 & 53.9 & 2.192 & 25 & \\
\hline$C-5500\left(N_{2}\right)$ & 0.216 & 0.547 & 2.50 & 25.3 & 50.7 & 2.004 & 25 & 66 \\
\hline \multicolumn{9}{|l|}{ EC-202 } \\
\hline$A R($ clean $)$ & 0.933 & 0.224 & 2.50 & 65.0 & 28.7 & 0.442 & 4 & \\
\hline$C-5500\left(\mathrm{~N}_{2}\right)$ & 0.619 & 0.313 & 2.50 & 45.9 & 31.0 & 0.675 & 4 & 30 \\
\hline \multicolumn{9}{|l|}{ EC-SI } \\
\hline AR (clean) & 0.538 & 0.232 & 2.50 & 62.7 & 48.1 & 0.771 & 5 & \\
\hline$C-5500\left(\mathrm{~N}_{2}\right)$ & 0.372 & 0.334 & 2.50 & 42.9 & 48.2 & 1.126 & 5 & 17 \\
\hline \multicolumn{9}{|l|}{ EC-HAS } \\
\hline$A R$ (clean) & 1.129 & 0.374 & 2.50 & 38.1 & 14.2 & 0.373 & 5.5 & \\
\hline$C-5500\left(N_{2}\right)$ & 0.930 & 0.395 & 2.50 & 35.9 & 16.3 & 0.455 & 5.5 & 77 \\
\hline \multicolumn{9}{|l|}{ EC-HASY } \\
\hline AR (clean) & 0.723 & 0.467 & 2.50 & 30.1 & 17.8 & 0.591 & 5 & \\
\hline$C-5500\left(N_{2}\right)$ & 0.839 & 0.511 & 2.50 & 27.3 & 14.0 & 0.513 & 5 & 92 \\
\hline
\end{tabular}

- S-particle area, $\rho_{p}$-particle density, $\rho_{g}$-glass density, A-aspect ratio, d-ave. diameter, w-ave. wall thickness, $M$-mole\% of non-network formers, \%Surv.-5500-6000 psig $\mathrm{N}_{2}$ crush survivor wt.\% of cleaned whole microspheres.

AR-As received, C-5500 $\left(\mathrm{N}_{2}\right)$ - Crush Survivors RJTA5121C 


\section{TABLE 3 - CHEMICAL ANALYSIS RESULTS}

\begin{tabular}{|c|c|c|c|c|c|c|c|c|c|c|c|c|c|}
\hline \multirow[t]{2}{*}{ Grade } & \multicolumn{4}{|c|}{ Metal (wt $\%$ ) } & \multicolumn{9}{|c|}{ Oxide (mole $\%$ normalized) } \\
\hline & Al & $\mathrm{Fe}$ & Si & $\mathrm{Na}$ & B & $\mathrm{Ca}$ & $\mathrm{Al}_{2} \mathrm{O}_{3}$ & $\mathrm{FeO}$ & $\mathrm{SiO}_{2}$ & $\mathrm{Na}_{2} \mathrm{O}$ & $\mathrm{B}_{2} \mathrm{O}_{3}$ & $\mathrm{CaO}$ & $M^{(a)}$ \\
\hline $3 M-D 32 / 4500$ & & & 43.56 & 4.54 & 0.83 & 5.73 & & & 84.7 & 5.4 & 2.1 & 7.8 & 13 \\
\hline $3 M-B 38 / 4000$ & & & 41.60 & 6.22 & 0.30 & 5.20 & & & 84.3 & 7.6 & 0.7 & 7.4 & 15 \\
\hline $3 M-A 38 / 4000$ & & & 43.19 & 6.05 & 0.40 & 5.35 & & & 84.4 & 7.3 & 1.0 & 7.3 & 15 \\
\hline EC-202 & & & 47.59 & 3.04 & 0.72 & & & & 94.5 & 3.7 & 1.8 & & 4 \\
\hline EC-SI & & & 46.37 & 4.10 & 0.62 & & & & 93.3 & 5.1 & 1.6 & & 5 \\
\hline EC-HAS & & & 45.38 & 4.37 & 0.62 & & & & 92.9 & 5.5 & 1.6 & & 5.5 \\
\hline EC-HASY & & & 40.07 & 3.29 & 0.57 & & & & 93.6 & 4.7 & 1.7 & & 5 \\
\hline Fillite $200 / 7$ & 15.48 & 2.55 & 30.46 & 0.36 & $\sim 0.3$ & $\begin{array}{c}K \\
\sim 0.8\end{array}$ & 19.7 & 3.2 & 74.5 & 0.6 & 1.0 & $\mathrm{~K}_{2}^{2} \mathrm{O}$ & 25 \\
\hline
\end{tabular}

(a) - Mole\% non-network glass formers. 
TABLE 4 MICROSCOPIC ANALYSES OF MICROSPHERES

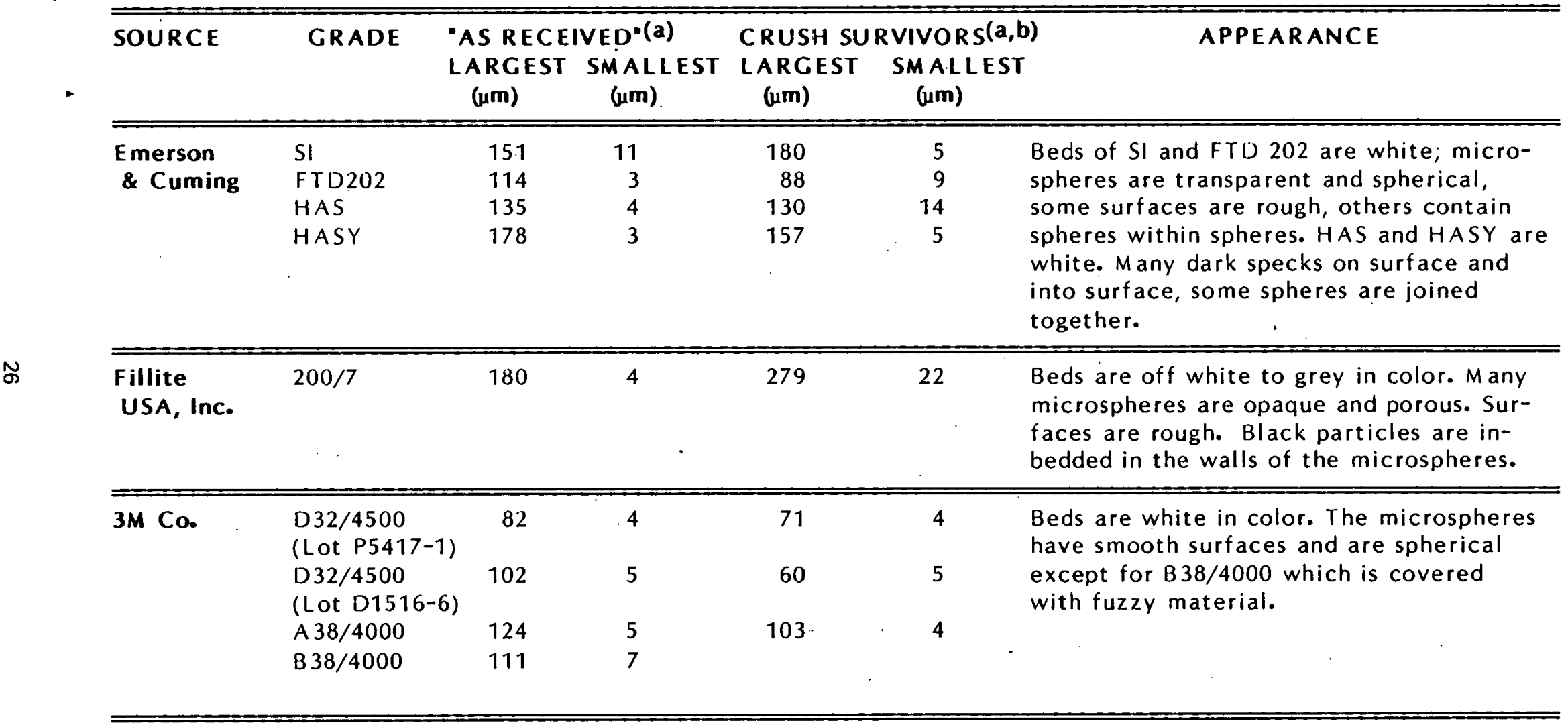

(a) Microscopically measured with a Filar eyepiece attachment

(b) Microspheres that survived a nominal $6000 \mathrm{psig}$ crush pressure

\section{R J T A52517}




\section{TABLE 5-MICROSPHERE CRUSH TEST RESULTS}

\begin{tabular}{|c|c|c|c|c|c|c|c|c|c|}
\hline \multirow{3}{*}{$\begin{array}{l}\text { Grade } \\
\begin{array}{c}3 M-D 32 / 4500 \\
(P 5427-1)\end{array}\end{array}$} & \multirow{4}{*}{ Medium } & \multirow{3}{*}{$\begin{array}{c}\text { Pressure } \\
\text { psig }\end{array}$} & \multicolumn{2}{|c|}{ Wt\% Sur." } & Grade & \multirow{2}{*}{ Medium } & \multirow{2}{*}{$\begin{array}{c}\begin{array}{c}\text { Pressure } \\
\text { psig }\end{array} \\
6000\end{array}$} & Wt\% & Sur." \\
\hline & & & & & \multirow{2}{*}{ Fil. $-200 / 7$} & & & & \\
\hline & & & & & & 12 & 6000 & 40 & $(00)$ \\
\hline & & 5500 & 88 & (93) & $\mathrm{E} \& \mathrm{C}-\mathrm{SI}$ & $\mathrm{H}_{2}$ & 5500 & 30 & (3n) \\
\hline & $\mathrm{He}$ & 6000 & 75 & $(77)$ & $E \& C-202$ & $\mathrm{~N}_{2}$ & 6000 & 30 & $(30)$ \\
\hline Treat.*" & $\mathrm{N}_{2}$ & 5900 & 77 & $(79)$ & & $\mathrm{H}_{2}$ & 5500 & 37 & $(37)$ \\
\hline$(01516-6)$ & $\mathrm{N}_{2}$ & 5500 & 57 & $(59)$ & \multirow[t]{2}{*}{ E\&C-HAS } & $\mathrm{N}_{2}$ & 5600 & 75 & $(77)$ \\
\hline & $\mathrm{H}_{\mathrm{O}}$ & 5600 & 63 & $(65)$ & & & & & \\
\hline Treat.*** & $\mathrm{N}_{2}^{2}$ & 5500 & 69 & $(71)$ & & $\mathrm{H}_{2}$ & 5500 & 90 & (93) \\
\hline $3 M-B 38 / 4000$ & $\mathrm{~N}_{2}$ & 6000 & 37 & $(44)$ & \multirow{2}{*}{ E\&C-HASY } & $\mathrm{N}_{2}$ & 5500 & 89 & $(92)$ \\
\hline & $\mathrm{H}_{2}$ & 5500 & 85 & $(86)$ & & & & & \\
\hline \multirow[t]{2}{*}{$3 M-A 38 / 4000$} & $\mathrm{~N}_{2}$ & 6000 & 76 & $(77)$ & Res & \multirow{2}{*}{\multicolumn{4}{|c|}{$\begin{array}{l}\text { Results corr. for debris in brāckets } \\
580^{\circ} \mathrm{C} \text { anneal. * } 500^{\circ} \mathrm{C} \text { anneal. }\end{array}$}} \\
\hline & $\mathrm{H}_{2}$ & 5500 & 85 & $(86)$ & $580^{\circ}$ & & & & \\
\hline
\end{tabular}

3M-3M Company, Fil.-Fillite USA, Incorporated, E\&C-Emerson \& Cuming Company R J T A5121 A 
TABLE 6 - FILL-DISPENSE TEST RESULTS

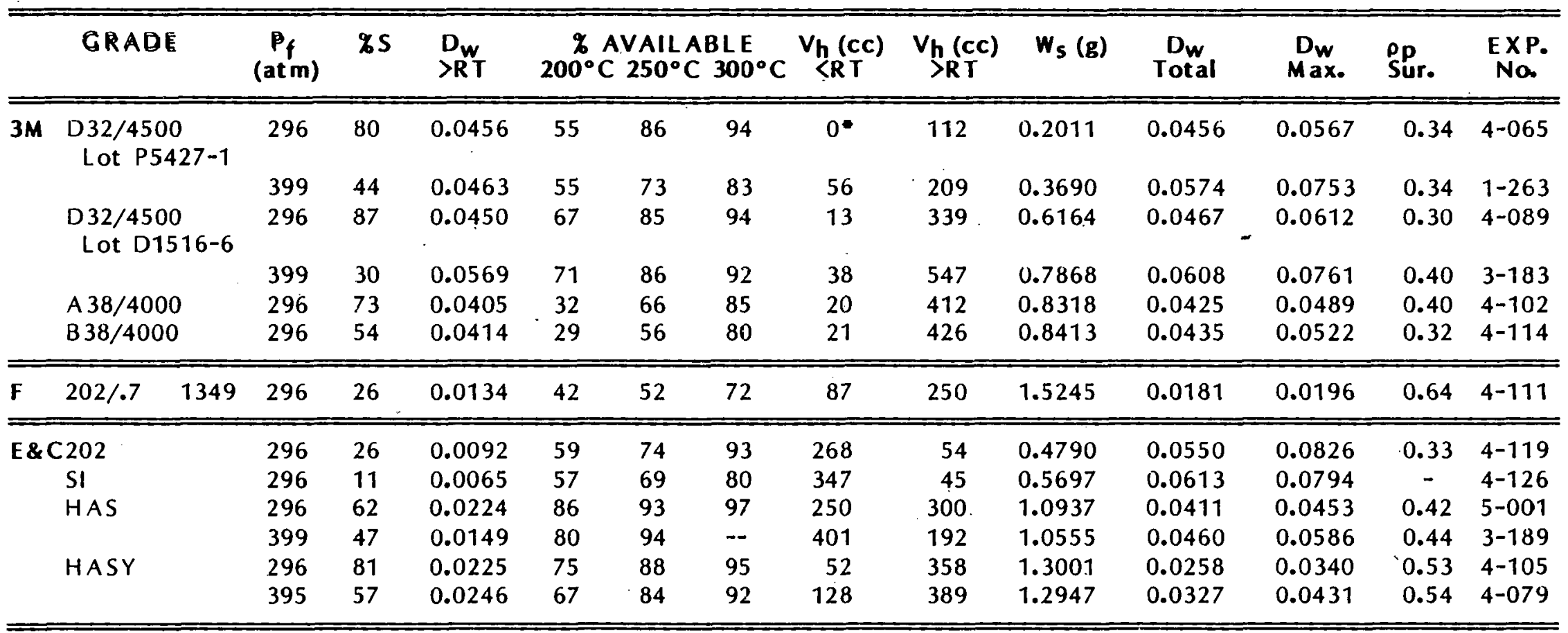

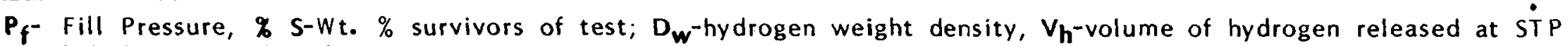
$(g / c c), W_{s}$-weight of specimen (g), $\rho_{p}$-average particle density of survivors (g/cc), 3M-3M Co., F-Fillite Corp., E\&C-Emerson and Cuming Co.

- No record of gas release below Room Temperature.

\section{RJTA5121D}


TABLE 7 - UPDATE OF 1979 TEST RESULTS

\begin{tabular}{|c|c|c|c|c|c|c|c|c|c|c|c|c|}
\hline \multirow{2}{*}{$3 M-D 32 / 4500$} & \multirow[t]{2}{*}{$\begin{array}{l}P_{f} \\
\text { (atm) }\end{array}$} & \multirow[t]{2}{*}{$\% 5$} & \multirow[t]{2}{*}{$\underset{>R_{T}}{\mathrm{D}_{\mathrm{W}}}$} & \multicolumn{3}{|c|}{$\begin{array}{l}\% \text { AVAILABLE } \\
200^{\circ} \mathrm{C} 250^{\circ} \mathrm{C} 300^{\circ}\end{array}$} & \multirow[t]{2}{*}{$\begin{array}{l}V_{h}(c c) \\
{ }^{\circ} C<R T\end{array}$} & \multirow[t]{2}{*}{$\underset{P_{R T}}{V_{h}(c c)}$} & \multirow[t]{2}{*}{$w_{s}(g)$} & \multirow[t]{2}{*}{$\mathbf{D}_{\text {Total }}$} & \multirow[t]{2}{*}{$\underset{M a x}{D_{w}}$} & \multirow[t]{2}{*}{$\begin{array}{l}\text { EXP. } \\
\text { NO. }\end{array}$} \\
\hline & & & & & & & & & & & & \\
\hline $\begin{array}{l}\text { As received } \\
(10 \text { Tests) }\end{array}$ & 301 & 77 & 0.0530 & 56 & 79 & 90 & 33 & 520 & 0.8032 & 0.0563 & 0.0604 & $1-159$ \\
\hline $\begin{array}{l}C-4500 \\
\quad(g \text { Tests })\end{array}$ & 335 & 95 & 0.0433 & 52 & 81 & 90 & - & 14.5 & 0.0274 & - & - & $1-48$ \\
\hline $\begin{array}{l}C-6000 \\
(4 \text { Tests })\end{array}$ & 212 & 99 & 0.0341 & 24 & 36 & 53 & - & 294 & 0.7043 & - & 0.0399 & $1-185$ \\
\hline $\begin{array}{l}<45 \mu \mathrm{m} \\
(2 \mathrm{Tests})\end{array}$ & 306 & 95 & 0.0512 & 71 & 83 & 94 & 4 & 491 & 0.7837 & 0.0517 & 0.0536 & $1-172$ \\
\hline $\begin{array}{l}<45 \mu m \text { clean } \\
(1 \text { Test })\end{array}$ & 313 & 90 & 0.0533 & 69 & 80 & & 14 & 607 & 0.9324 & 0.0545 & 0.0549 & $1-180$ \\
\hline $\begin{array}{c}C-5750,<45 \mu \mathrm{m} \\
(2 \text { Tests })\end{array}$ & 329 & 98 & 0.0502 & 47 & 65 & 75 & 19 & 573 & 0.9330 & 0.0519 & - & $1-250$ \\
\hline $\begin{array}{c}C-4.500,>45 \mu \mathrm{m} \\
1 \text { Test) }\end{array}$ & 213 & 98 & 0.0471 & 50 & 78 & 90 & - & 422 & 0.7327 & - & 0.0484 & $1-212$ \\
\hline $\begin{array}{c}\text { Hect Treat. } \\
(\tilde{2} \text { Tests }) \\
3 \mathrm{M}-\mathrm{B38} / 4000\end{array}$ & 301 & 80 & 0.0596 & 60 & 79 & 89 & 3 & 180 & 0.2470 & 0.0606 & - & $1-163$ \\
\hline $\begin{array}{l}<45 \mu \mathrm{m} \\
(1 \text { Test })\end{array}$ & 318 & 85 & 0.0431 & 64 & 78 & 92 & - & 562 & 1.0614 & - & - & $1-225$ \\
\hline $\begin{array}{l}45-75 \mu \mathrm{m} \\
(1 \text { Test })\end{array}$ & 337 & 51 & 0.0333 & 50 & 59 & 75 & 70 & 403 & 0.9893 & 0.0391 & - & $1-231$ \\
\hline
\end{tabular}

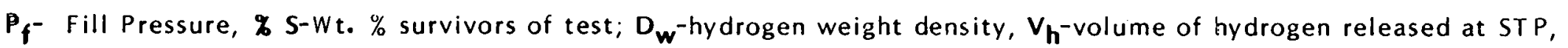
$W_{s}$-weight of specimen, $3 M-3 M$ Co.

- No record of gas release below R.T.

R J TA5217A 
TABLE 8 - SURVEY OF PARTICLE SIZE IM PROVEMENTS

\begin{tabular}{llll}
\hline GRADE & SIZE & $\begin{array}{l}\text { PERCENT } \\
\text { OF BED }\end{array}$ & $\begin{array}{l}\text { PARTICLE } \\
\text { DENSITY } \\
(\mathrm{g} / \mathrm{CC})\end{array}$ \\
\hline D32/4500 & $<45$ & 71 & 0.338 \\
(Lot P.5427-1,) & $45-75$ & 29 & 0.262 \\
EC-HAS & & & \\
& $<45$ & 31 & 0.436 \\
& $45-75$ & 38 & 0.384 \\
EC-HASY & $>75$ & 31 & 0.375 \\
& 445 & 33 & 0.528 \\
& $45-75$ & 43 & 0.491 \\
& $>75$ & 24 & 0.489 \\
\hline \hline
\end{tabular}

RJTA5217E

萑 


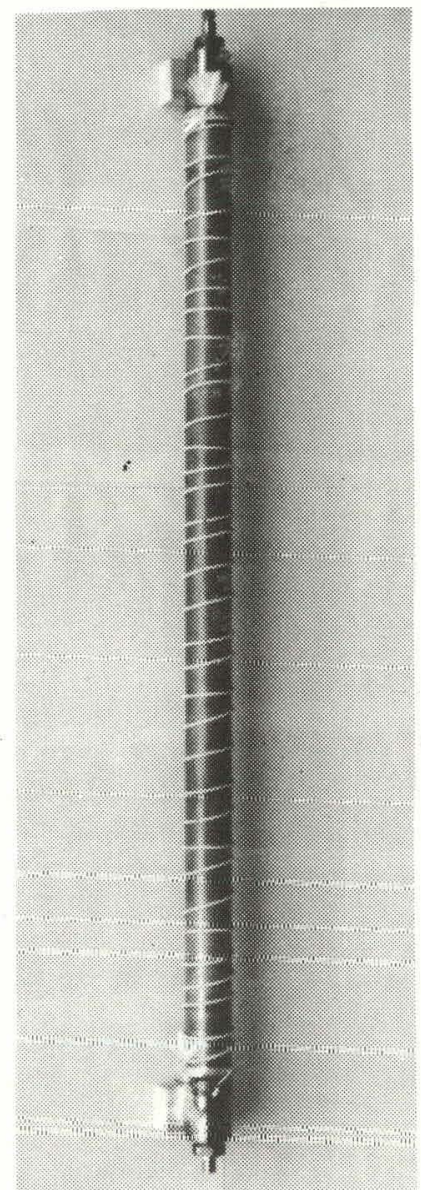

A

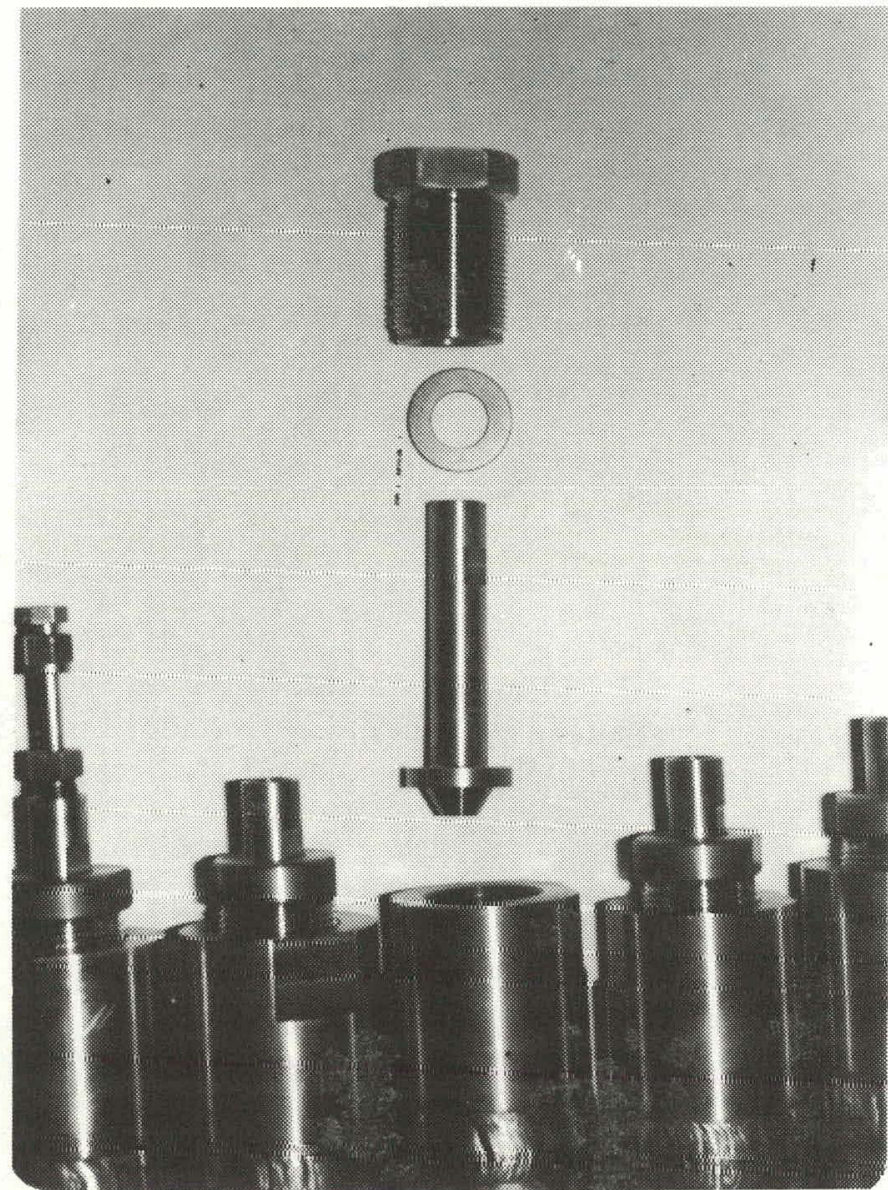

B

Figure 1 Large Fill Vessel

A. Full length tube

$B$. Tube end closure 


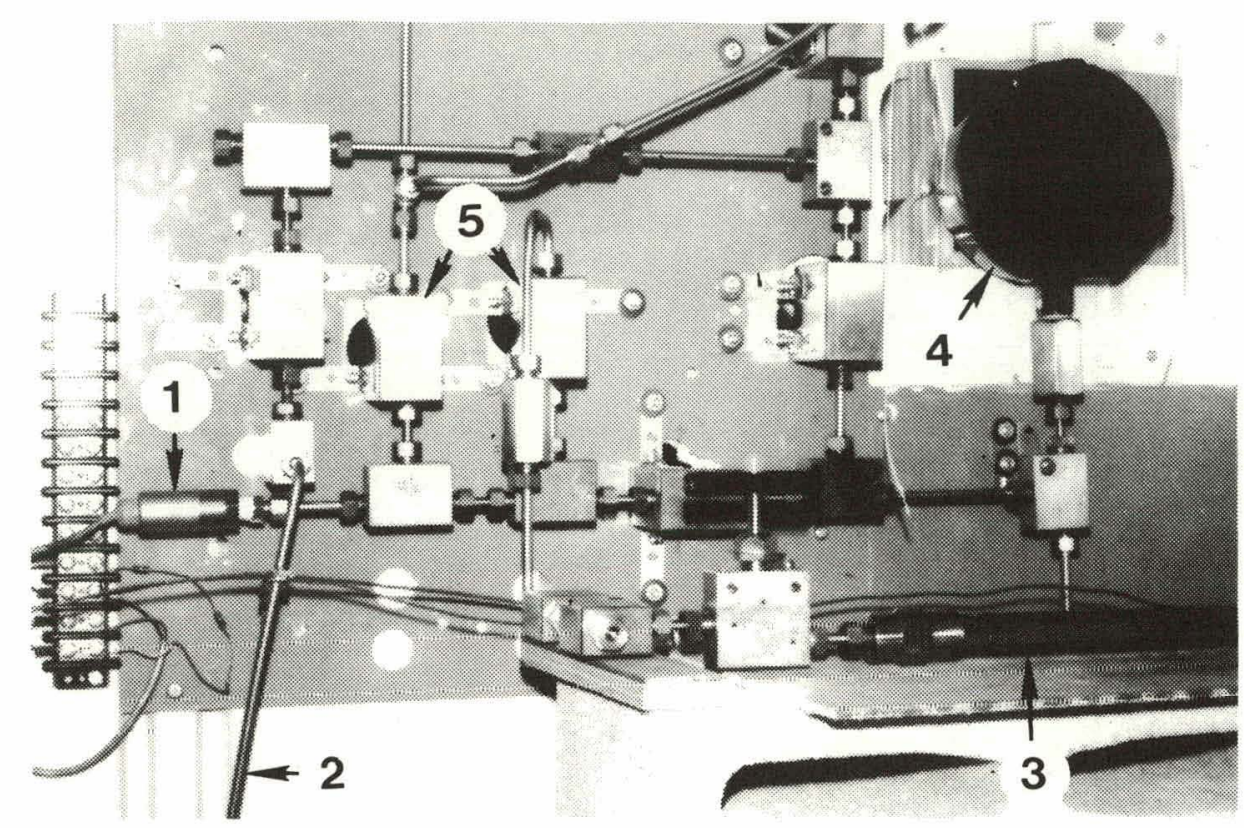

Figure 2 Inside View of Fill Manifold

1. Pressure transducer, 2. Connection to large fill vessel, 3. Small fill vessel, 4. Pressure gauge, 5. Isolation valves.

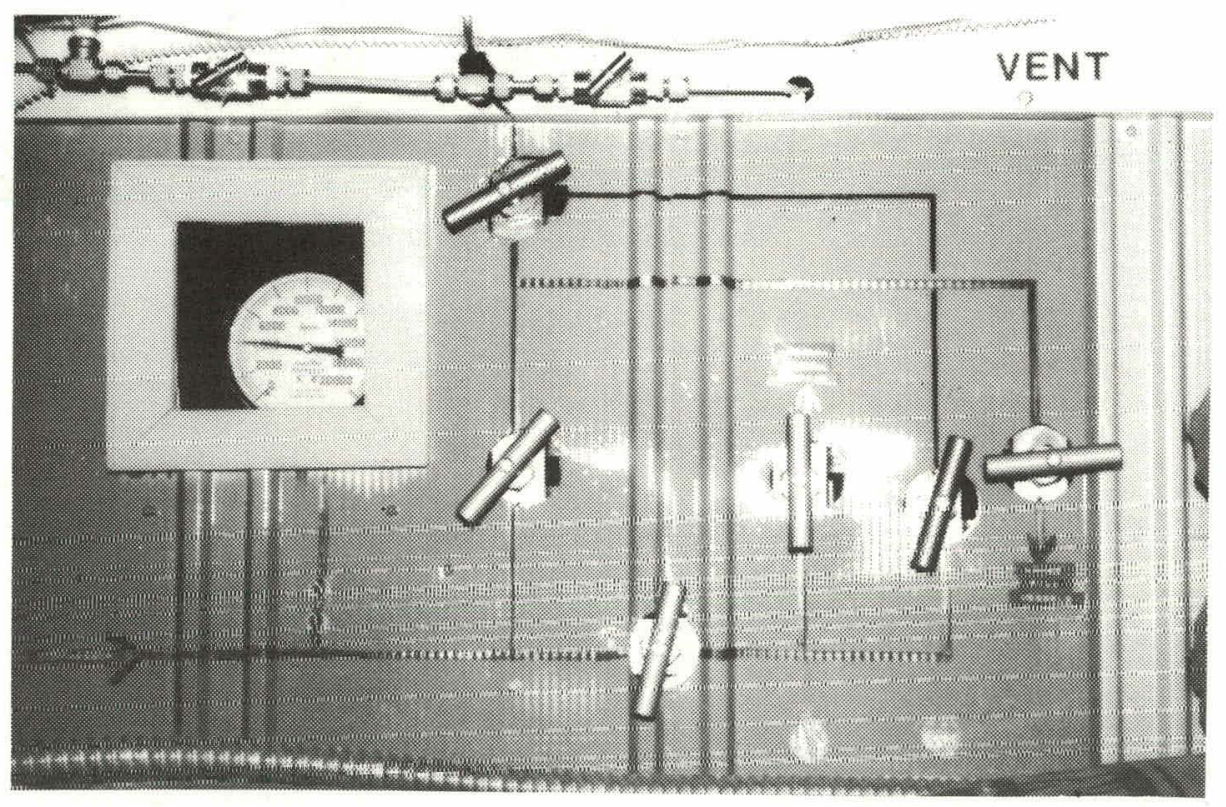

Figure 3 Outside View of Fill Manifold 


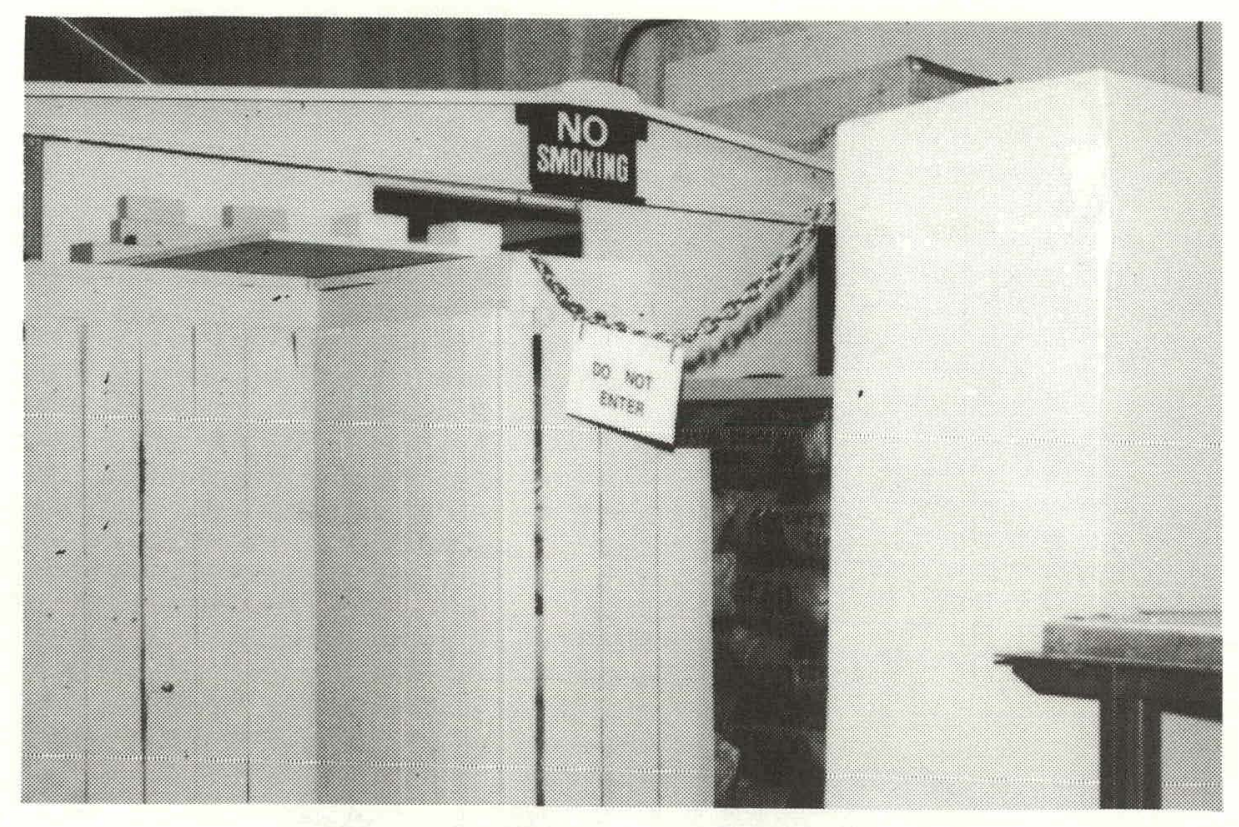

Figure 4 Hood Enclosure

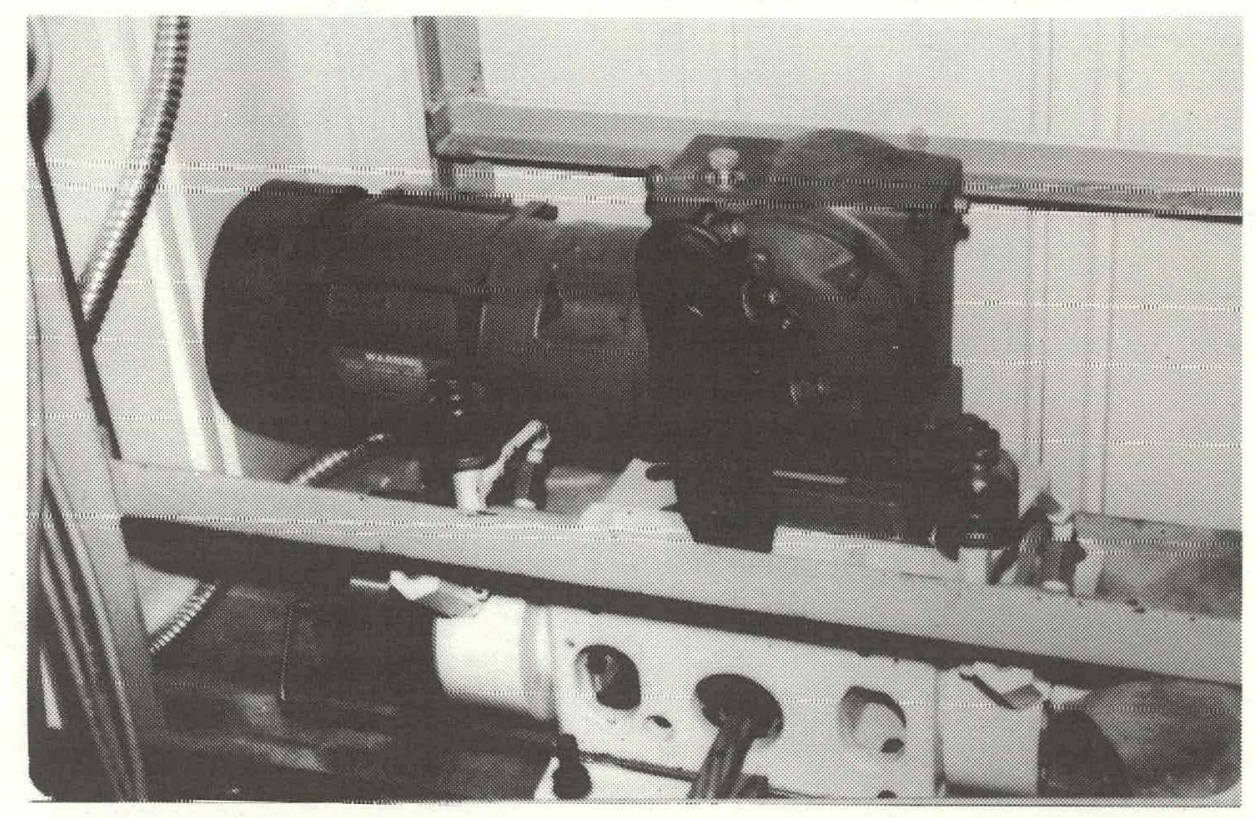

Figure 3 I wo Stage Didpluagm Type Compressor 


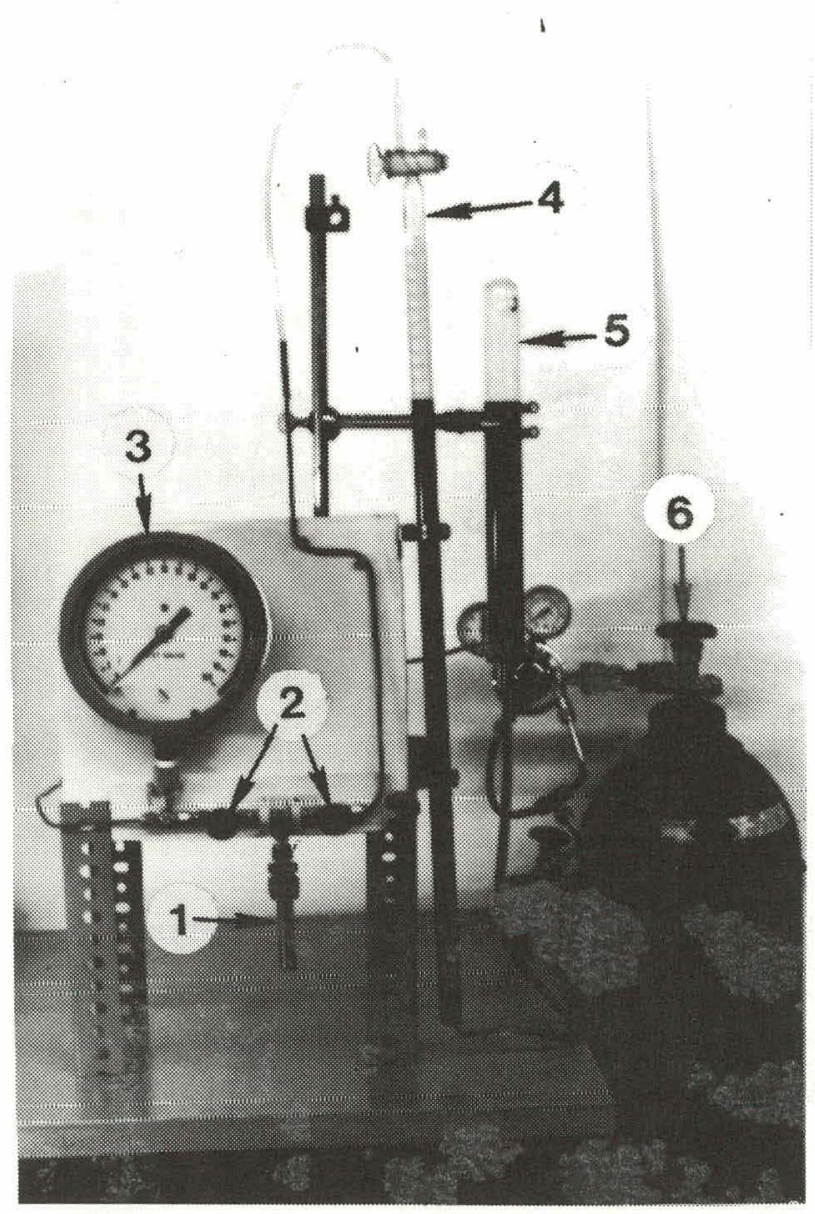

Figure 6 Gas Pycnometer

1. Sample Tube

2. Isolation Valves

3. Pressure Gauge

4. Gas Buret

5. Pressure Equalizing Tube

6. Nitrogen Tank 


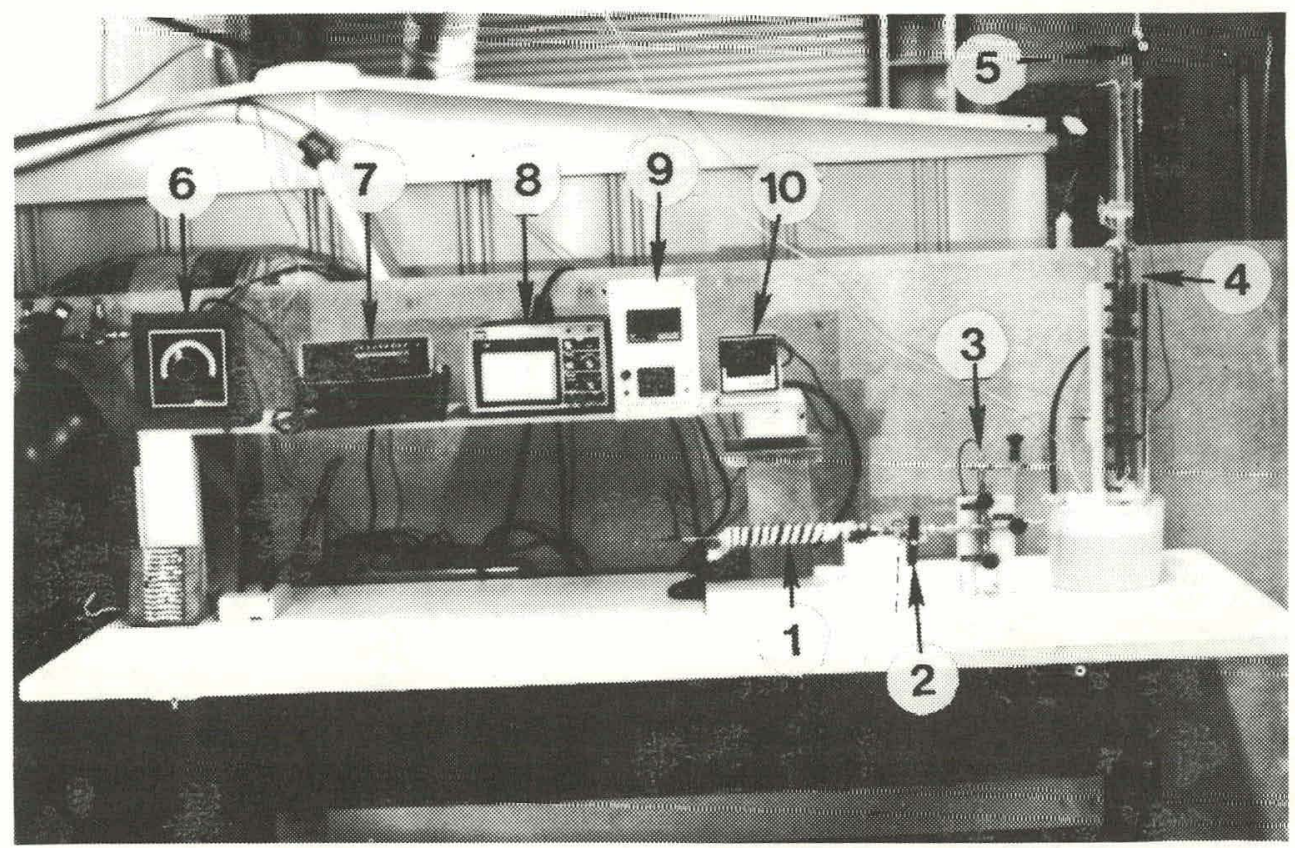

Figure 7 Hydrogen Dispensing Apparatus

1. Small Fill-Dispense Tube with Heater, 2. Sample Tube Valves,

3. Needle Valves, 4. Gas Buret, 5. Vent Valve, 6. Thermocouple Switch,

7. Digital Voltineter, 8. Strip-Chart Recorder, 9. Flow-Meter,

10. Temperature Controller. Flow-meter Sensing Head behind the Buret). (Not shown)

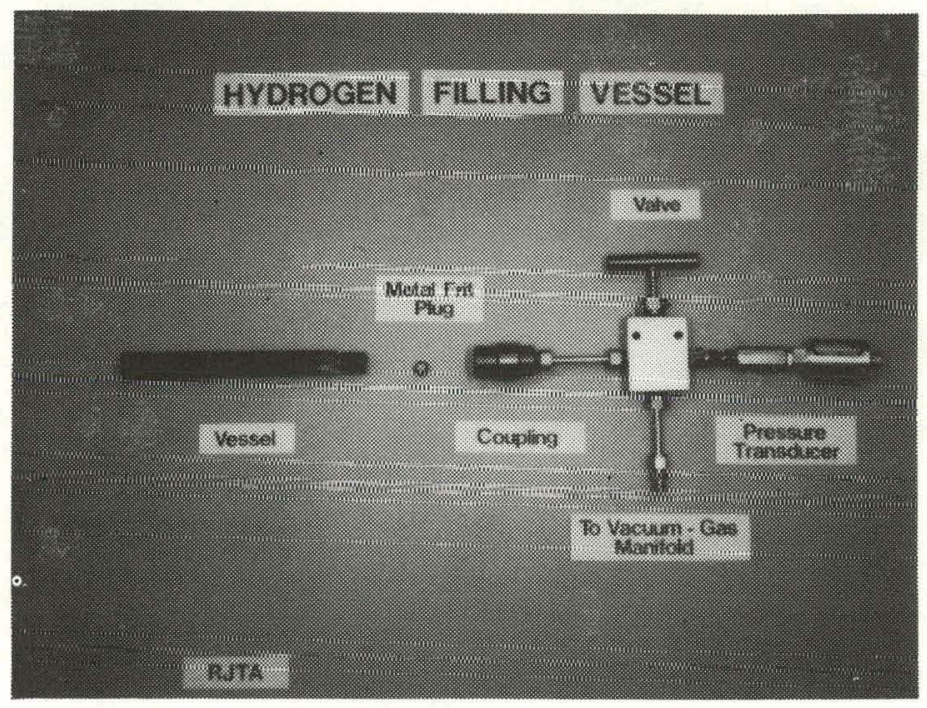

Figure 8 Small Fill Vessel 


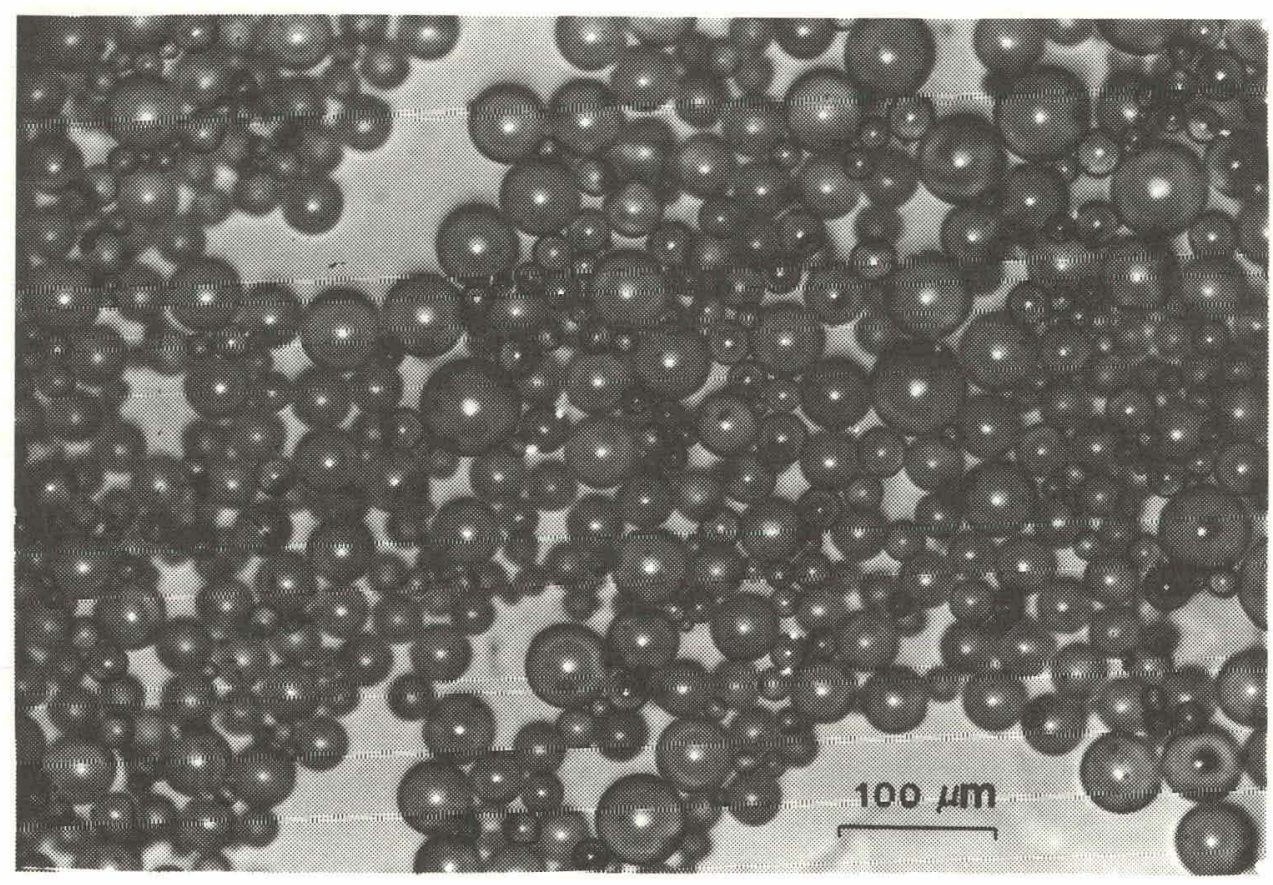

(A) $3 \mathrm{M}-\mathrm{D} 32 / 4500$ (As Received, Cleaned)

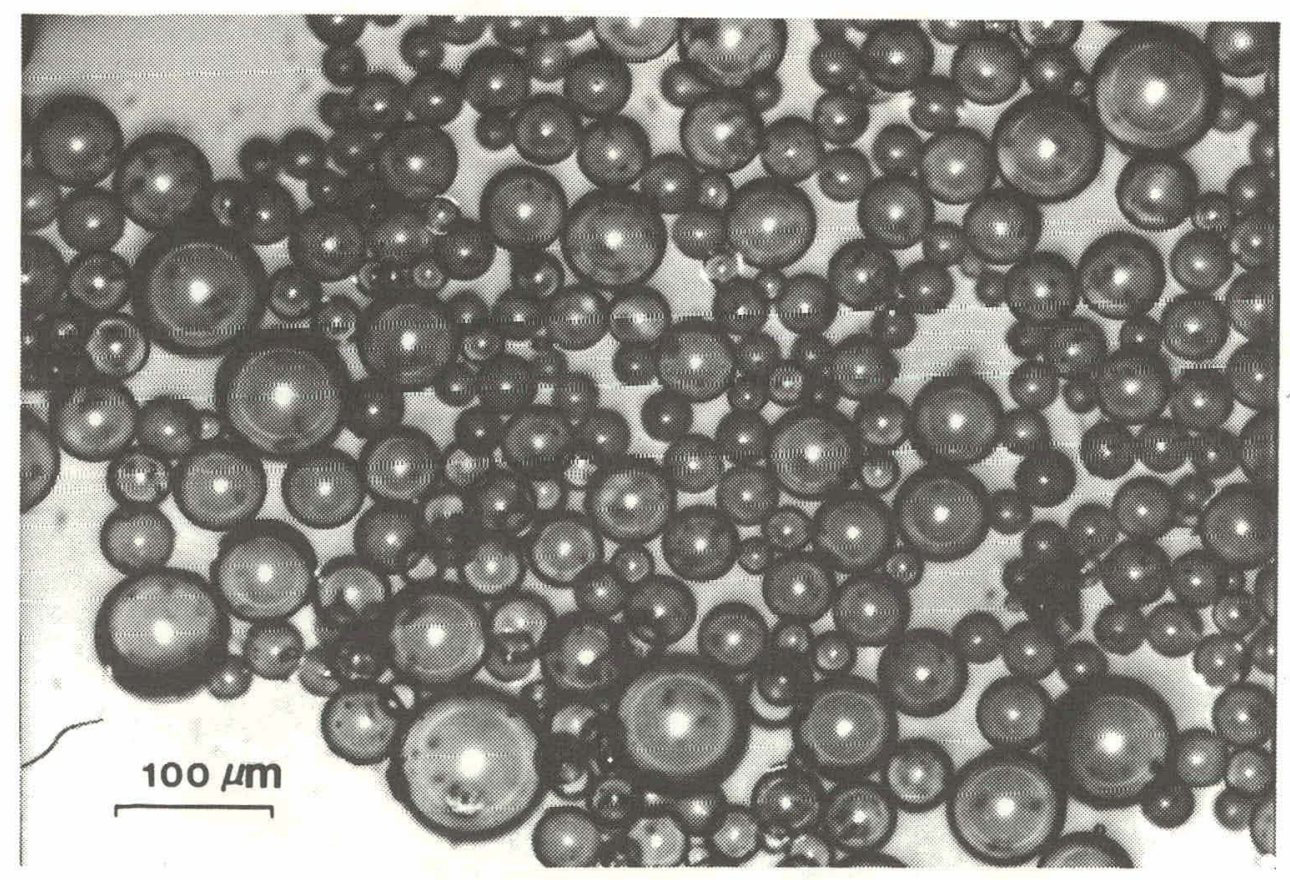

(B) $3 M-A 38 / 4000$ (C rush Survivors)

Figure 9 Microspheres 


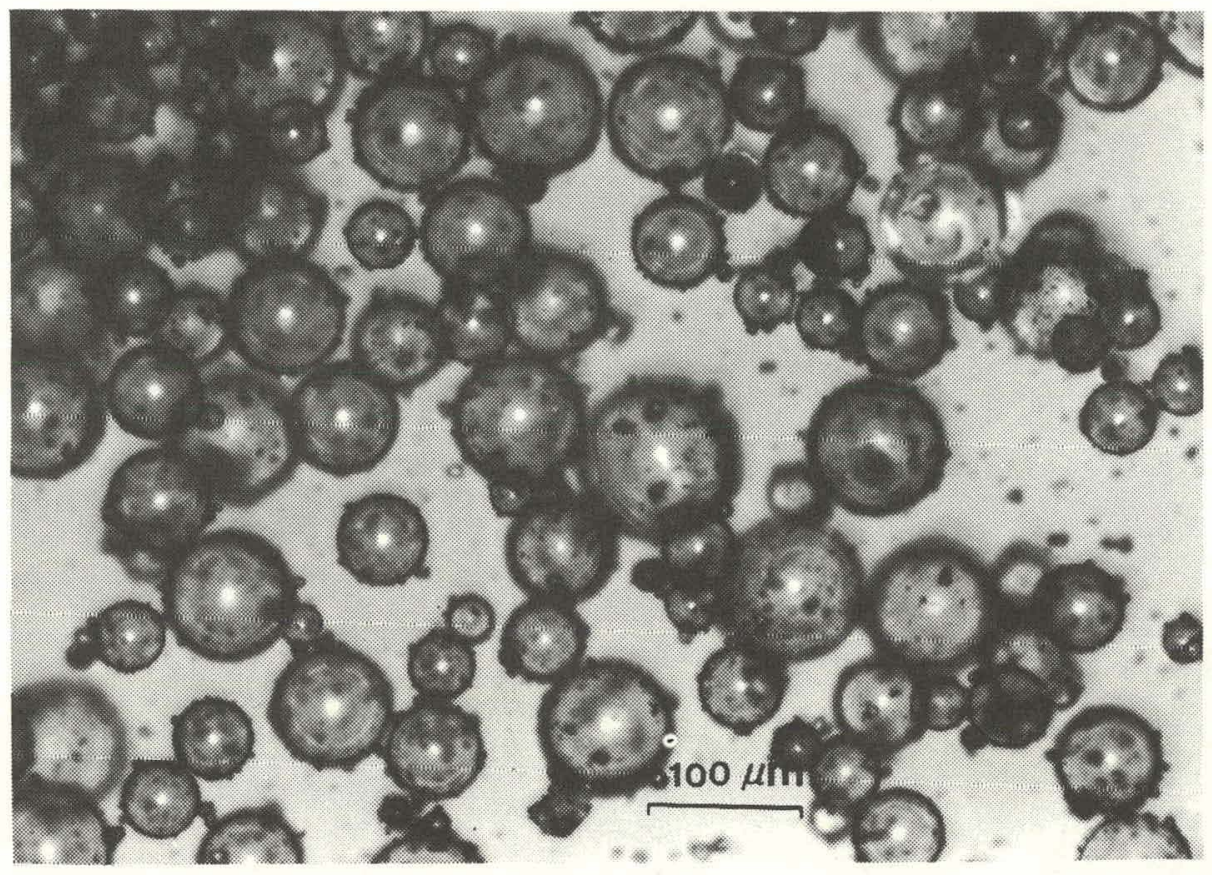

(A) $3 \mathrm{M}-\mathrm{B} 38 / 4000$ (As Received)

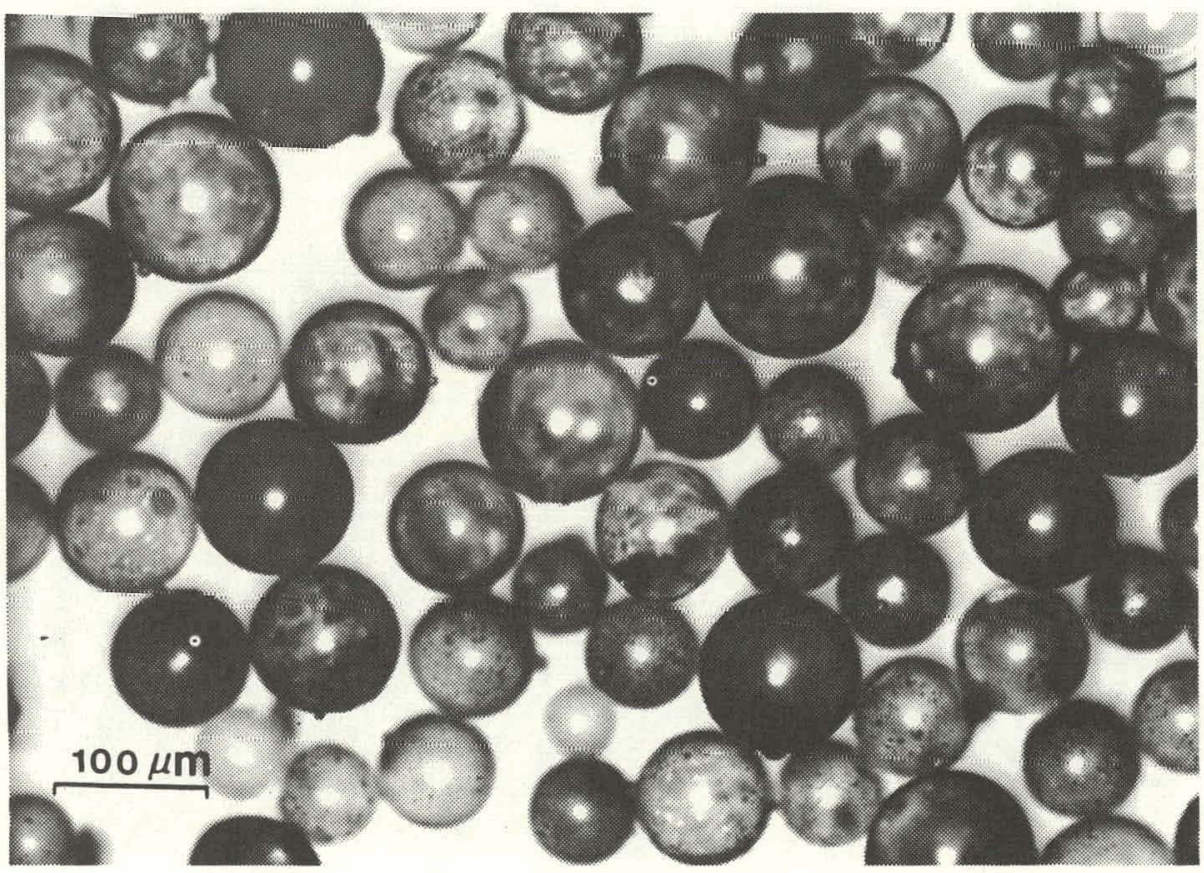

(B) Fillite 200/7 (C rush Survivors)

Figure 10 Microspheres 


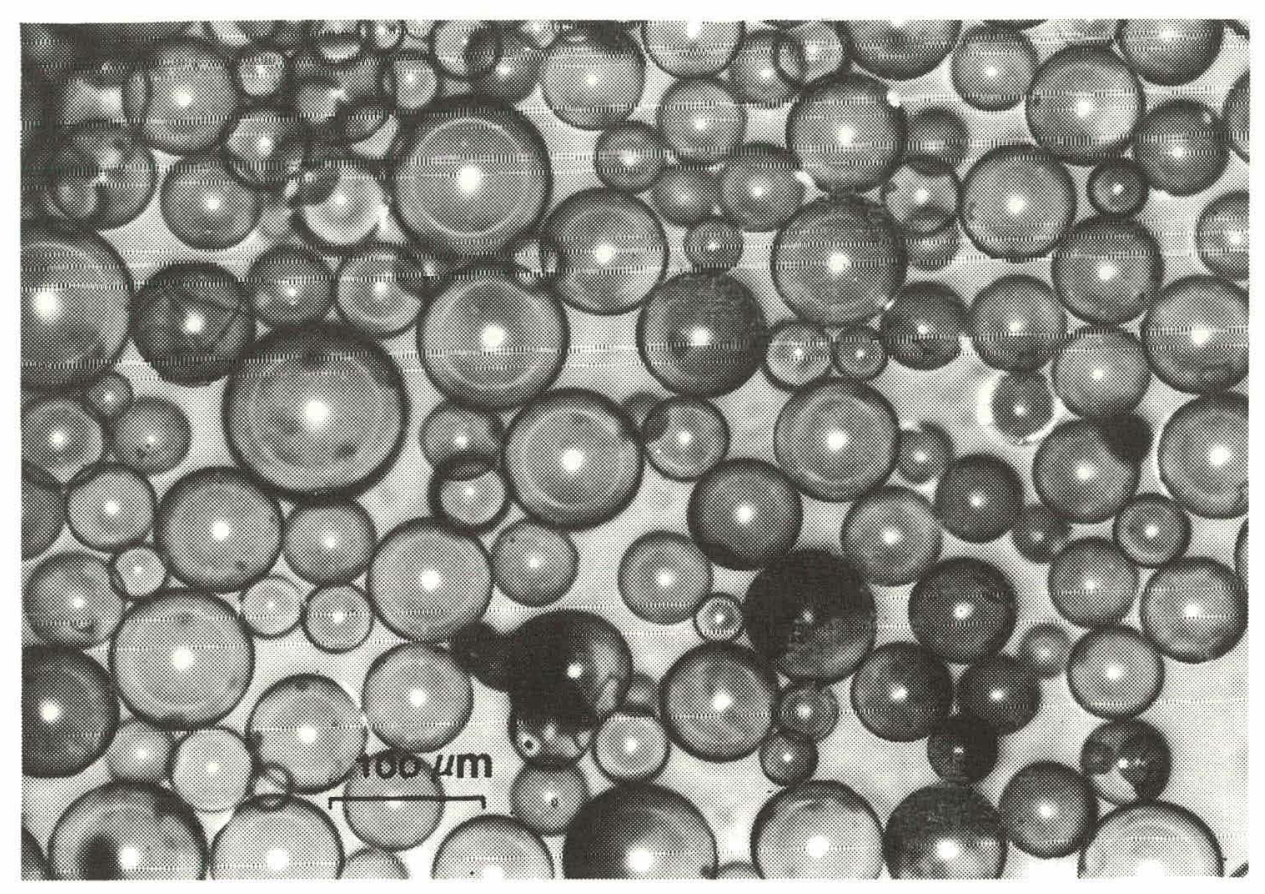

(A) EC-SI (As Received, Cleaned)

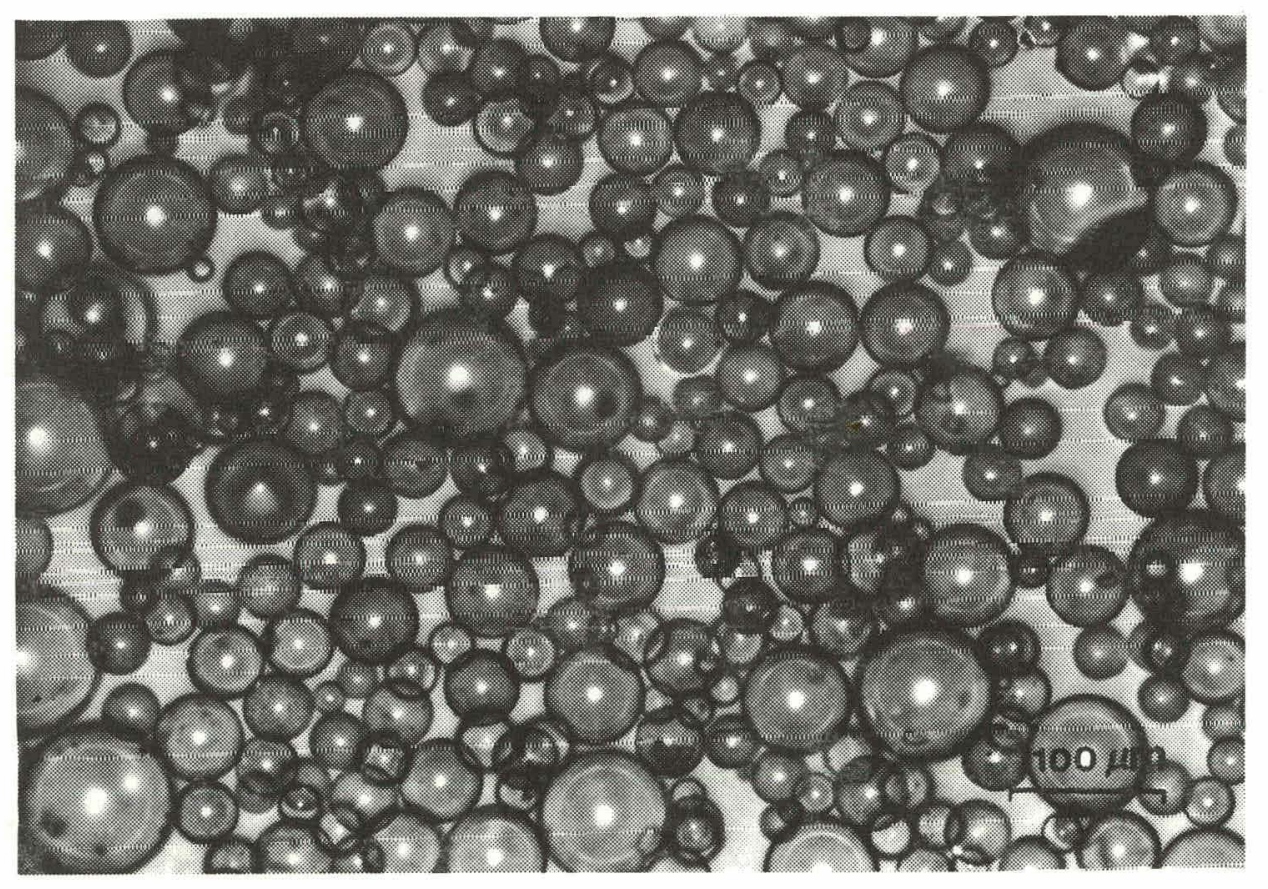

(B) EC-202 (As Received, Cleaned)

Figure 11 Microspheres 
(рәиеәІЈ 'рам!әวәу s甘) ᄉ

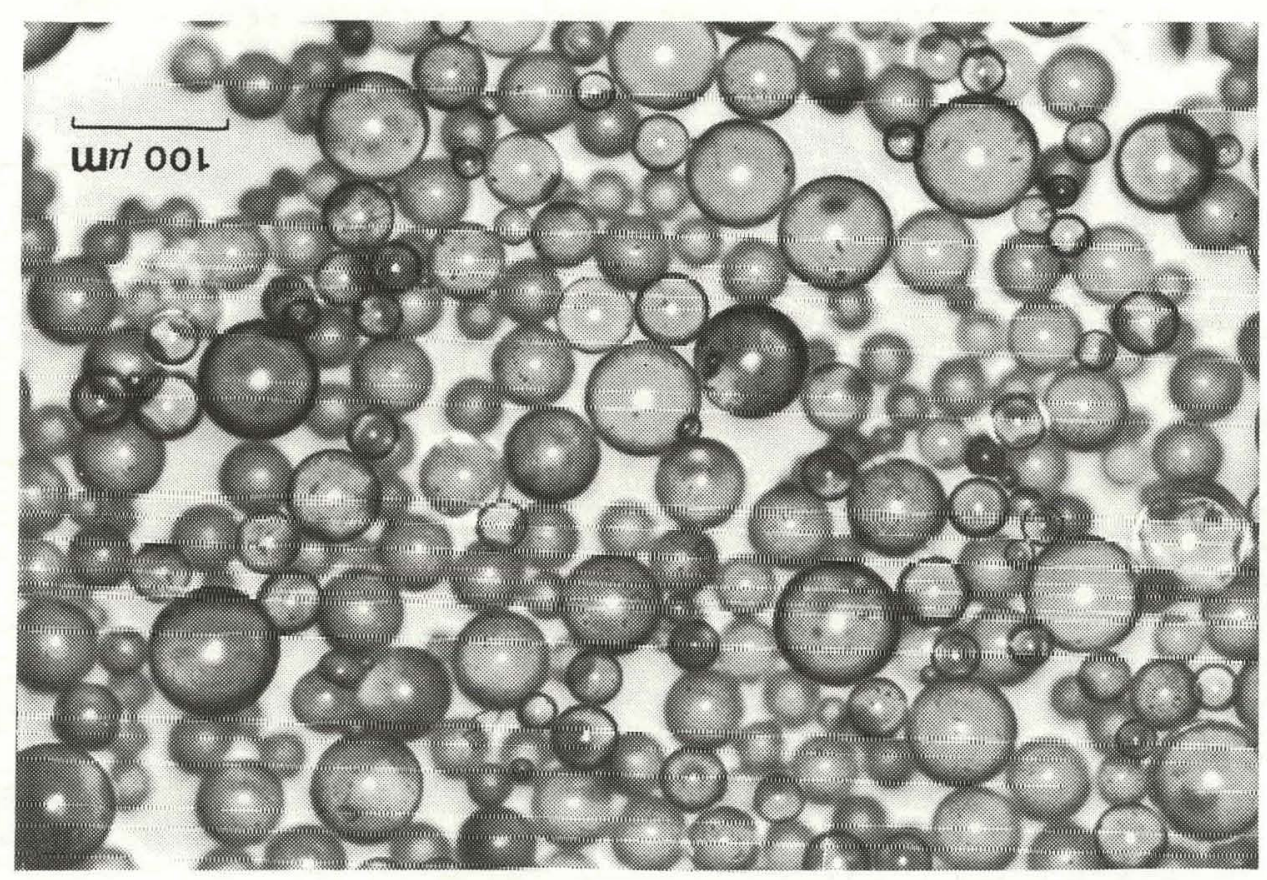

•(рәиеә.) 'рәм!әวәу

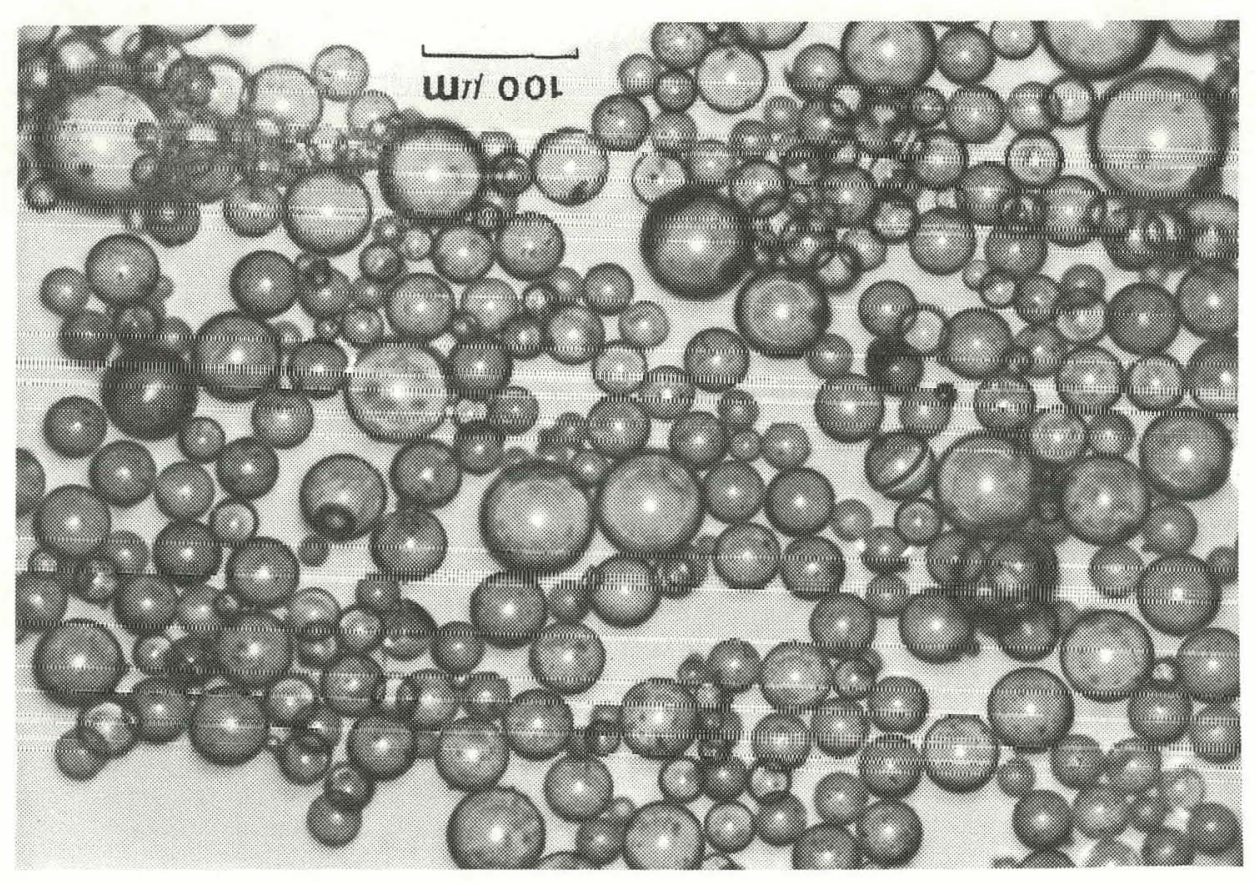




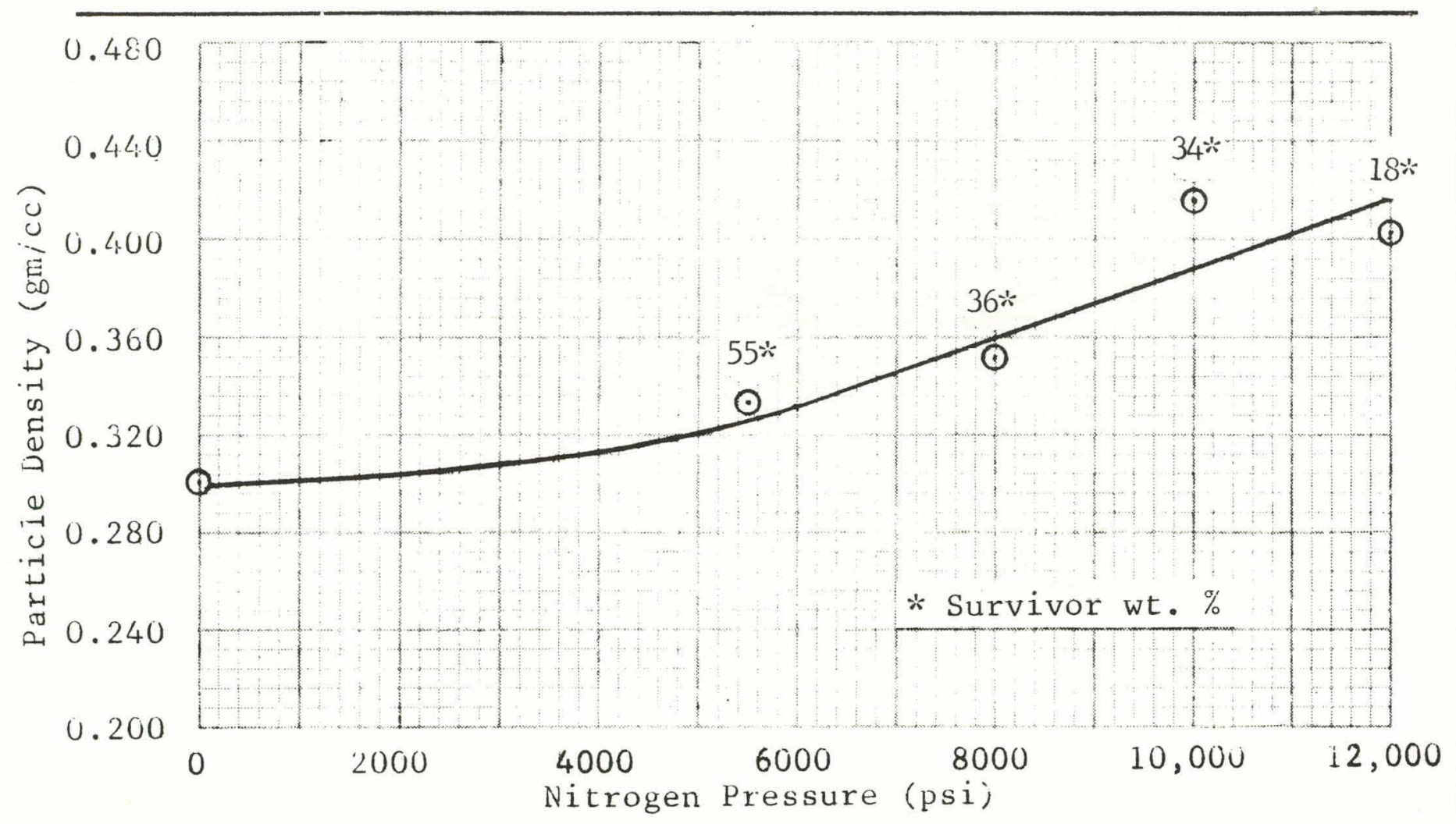

Figure 13 Crush Treatment of 3M-D32/45 Grade Microspheres (Lot No. P5427-1)

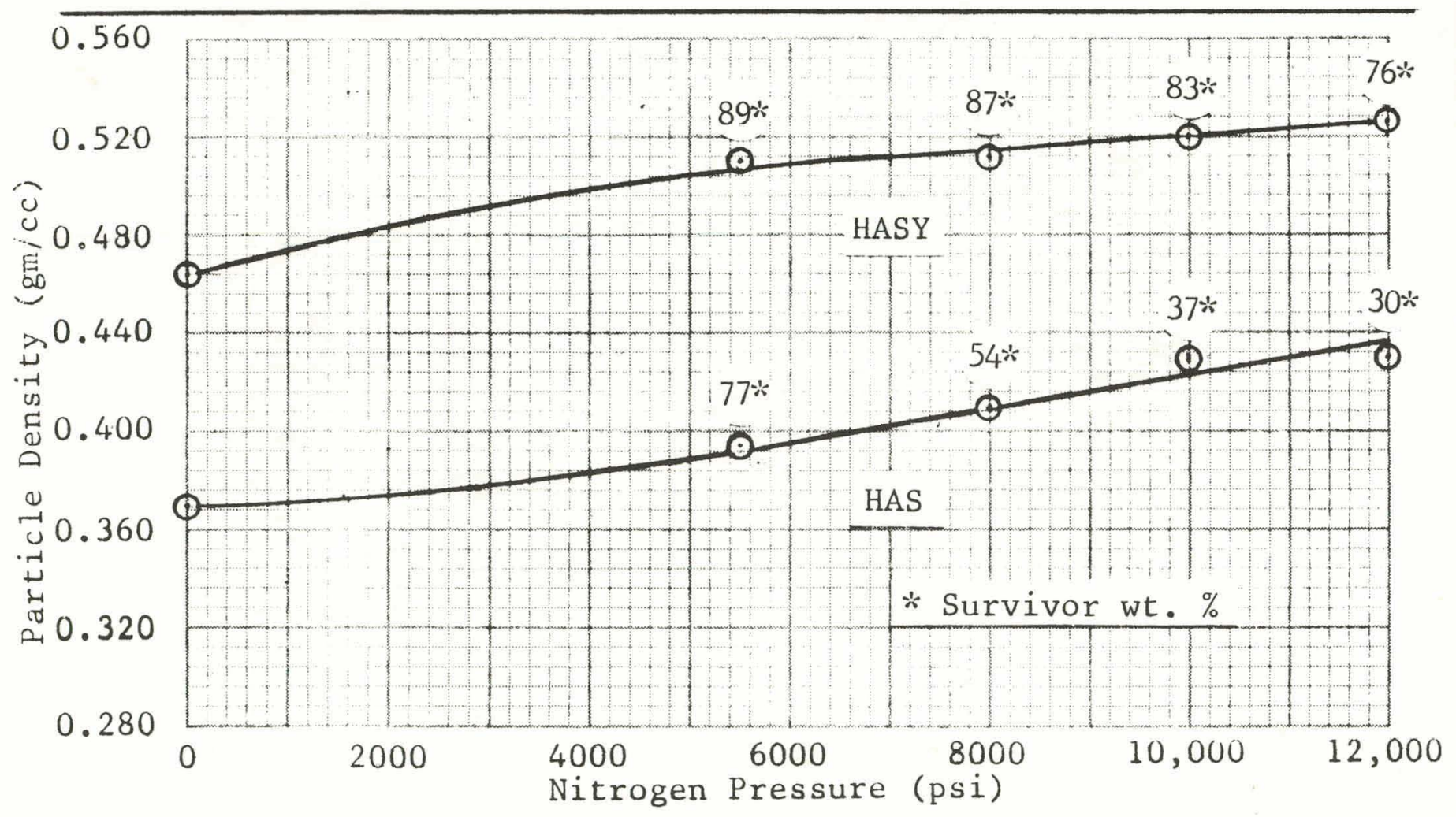

Figure 14 Crush Treatment of Emerson \& Cuming Grade Microspheres 